\title{
DAG tales: the multiple faces of diacylglycerol-stereochemistry, metabolism, and signaling
}

\author{
Thomas Oliver Eichmann ${ }^{1}$ Achim Lass ${ }^{1}$
}

Received: 18 May 2015/Revised: 17 June 2015/ Accepted: 29 June 2015/Published online: 8 July 2015

(C) The Author(s) 2015. This article is published with open access at Springerlink.com

\begin{abstract}
The neutral lipids diacylglycerols (DAGs) are involved in a plethora of metabolic pathways. They function as components of cellular membranes, as building blocks for glycero(phospho)lipids, and as lipid second messengers. Considering their central role in multiple metabolic processes and signaling pathways, cellular DAG levels require a tight regulation to ensure a constant and controlled availability. Interestingly, DAG species are versatile in their chemical structure. Besides the different fatty acid species esterified to the glycerol backbone, DAGs can occur in three different stereo/regioisoforms, each with unique biological properties. Recent scientific advances have revealed that DAG metabolizing enzymes generate and distinguish different DAG isoforms, and that only one DAG isoform holds signaling properties. Herein, we review the current knowledge of DAG stereochemistry and their impact on cellular metabolism and signaling. Further, we describe intracellular DAG turnover and its stereochemistry in a 3-pool model to illustrate the spatial and stereochemical separation and hereby the diversity of cellular DAG metabolism.
\end{abstract}

Keywords Lipase $\cdot$ Hydrolase $\cdot$ Acyltransferase . Kinase · Insulin

Thomas Oliver Eichmann

thomas.eichmann@uni-graz.at

$\triangle$ Achim Lass

achim.lass@uni-graz.at

1 Institute of Molecular Biosciences, University of Graz, Heinrichstrasse 31/2, 8010 Graz, Austria

\begin{tabular}{|c|c|}
\hline \multicolumn{2}{|c|}{ Abbreviations } \\
\hline 2-AG & 2-Arachidonoyl glycerol \\
\hline AGPAT & $\begin{array}{l}\text { Acyl-CoA acylglycerol-3-phosphate } \\
\text { acyltransferase }\end{array}$ \\
\hline ATGL & Adipose triglyceride lipase \\
\hline BAT & Brown adipose tissue \\
\hline BSSL/CEL & $\begin{array}{l}\text { Bile salt-stimulated lipase/carboxyl ester } \\
\text { lipase }\end{array}$ \\
\hline CGI-58 & Comparative gene identification-58 \\
\hline $\mathrm{CE}$ & Cholesteryl ester \\
\hline CEPT & $\begin{array}{l}\text { CDP-ethanolamine/choline:1,2- } \\
\text { diacylglycerol } \\
\text { ethanolaminephosphotransferase }\end{array}$ \\
\hline CPT & $\begin{array}{l}\text { CDP-choline:1,2-diacylglycerol } \\
\text { ethanolaminephosphotransferase }\end{array}$ \\
\hline DAG & Diacylglycerol \\
\hline DAGL & DAG lipase \\
\hline DGAT & DAG-O-acyltransferase \\
\hline DGK & DAG kinase \\
\hline EPT & $\begin{array}{l}\text { CDP-ethanolamine:1,2-diacylglycerol } \\
\text { ethanolaminephosphotransferase }\end{array}$ \\
\hline ER & Endoplasmic reticulum \\
\hline FA & Fatty acid \\
\hline G3P & Glycerol-3-phosphate \\
\hline GL & Gastric lipase \\
\hline GLUT4 & Glucose transporter 4 \\
\hline GPAT & Glycerol-3-phosphate acyltransferase \\
\hline HSL & Hormone-sensitive lipase \\
\hline IR & Insulin resistance \\
\hline IRS & Insulin receptor substrate \\
\hline LD & Lipid droplet \\
\hline LL & Lingual lipase \\
\hline LPA & Lysophosphatidic acid \\
\hline LPL & Lipoprotein lipase \\
\hline MAG & Monoacylglycerol \\
\hline
\end{tabular}




$\begin{array}{ll}\text { MGAT } & \text { Monoacylglycerol-O-acyltransferase } \\ \text { PA } & \text { Phosphatidic acid } \\ \text { PAP } & \text { PA phosphohydrolase/lipin } \\ \text { PC } & \text { Phosphatidylcholine } \\ \text { PDK } & \text { 3-Phosphoinositide-dependent protein kinase } \\ \text { PE } & \text { Phosphatidylethanolamine } \\ \text { PI } & \text { Phosphatidylinositol } \\ \text { PI3K } & \text { Phosphatidylinositide-3-kinase } \\ \text { PIP } & \text { Phosphatidylinositolphosphate } \\ \text { PIP2 } & \text { Phosphatidylinositol 4,5-bisphosphate } \\ \text { PKB/Akt } & \text { Protein kinase B } \\ \text { PKC } & \text { Protein kinase C } \\ \text { PKD } & \text { Protein kinase D } \\ \text { PL } & \text { Phospholipid } \\ \text { PLA1(2) } & \text { Phospholipase A1 (2) } \\ \text { PLC } & \text { Phospholipase C } \\ \text { PLD } & \text { Phospholipase D } \\ \text { PLRP } & \text { Pancreatic lipase-related protein } \\ \text { PNPLA } & \text { Patatin-like phospholipase domain } \\ & \text { containing } \\ \text { PS } & \text { Phosphatidylserine } \\ \text { PTL } & \text { Pancreatic triglyceride lipase/colipase } \\ \text { RE } & \text { Retinyl ester } \\ \text { SMS } & \text { Sphingomyelin synthase } \\ \text { SMSr } & \text { SMS-related protein } \\ \text { TGH/Ces3 } & \text { Triacylglycerol hydrolase/carboxylesterase 3 } \\ \text { TAG } & \text { Triacylglycerol } \\ \text { TRPC } & \text { Transient receptor potential canonical } \\ \text { WAT } & \text { White adipose tissue } \\ & \end{array}$

\section{Introduction}

For a long time, diacylglycerol (DAG) has been recognized as lipid molecule which exhibits signaling function. More recently, research has unraveled that certain lipid-modifying enzymes discriminate between different stereo/regioisomers of DAG, pinpointing that different DAG isomers may have distinct cellular functions and fates. Thus, the stereochemical nature of DAG isomers by itself is a determinant for its physiological role in distinct cellular compartments and metabolic pathways.

\section{Stereochemistry of DAG}

Generally, isomers (from Greek: isos—equal, mèros—part) are molecules sharing identical molecular formulas but differing in their structures. Isomers can be divided into two main groups. On the one hand, there are structural isomers which exhibit differentially linked atoms and functional groups. On the other hand, there are spatial isomers (stereoisomers) which display same linkage of atoms and functional groups but differ in their geometrical position in space. A special group of stereoisomers, named enantiomers, is related by reflection which implies that two enantiomers are not superimposable. Furthermore, enantiomers are characterized by an asymmetric or chiral carbon atom, featured by four different ligands (Fig. 1).

DAGs are generated during a variety of metabolic reactions and have attracted much attention as important signaling molecules. Importantly, DAG represents a lipid class that exhibits different isomeric properties. Triacylglycerol (TAG), one possible metabolic precursor of DAG, contains three fatty acids (FAs) esterified to the trihydric alcohol glycerol. This implicates that TAG provides three possible sites for lipasedependent hydrolysis, which can result in three different DAG isoforms. The stereospecific numbering $(s n)$ designates the conformation of glycerol derivatives, hence the position of the fatty ester at the glycerol backbone ( $s n-1, s n-2, s n-3$; according to IUPAC nomenclature). Accordingly, DAGs generated from the hydrolysis of the phospholipid (PL) headgroup are per definition $s n$-1,2 isomers since $s n$-glycerol-3-phosphate/L$\alpha$-glycerophosphate (G3P) is the basic building block of all PLs.

TAG exhibits another important property as lipase substrate, namely prochirality. Prochirality describes the condition that an achiral molecule can be converted into a chiral molecule by a one-step reaction. In case of TAG, the potential achiral carbon atom at $s n-2$ position becomes a chiral center by removal of the attached FA either at $s n-1$ or at $s n-3$ position.

Prochiral TAG species exhibit chemically identical but enantiotopic reactive groups (e.g., oleic acid (C18:1) at $s n$ 1 and $s n-3$ position). These groups (FAs) can be stereochemically discriminated during lipase-dependent hydrolysis reaction, which results in a chiral DAG product. Lipase-dependent cleavage of the FA esterified at either $s n$ 1 or $s n-3$ position of a TAG molecule leads to the generation of a chiral center at the $s n-2$ position and to one of the two DAG enantiomers, $s n-2,3$ or $s n-1,2$ DAG, respectively. These DAG enantiomers face themselves as reflection and are not superimposable (Fig. 1). Importantly, 1,3 DAGs can be achiral or chiral, depending on the fatty acid species esterified to the $s n-1$ and $s n-3$ position. If two identical fatty acid species are esterified to both position then 1,3 DAG is achiral while if fatty esters at the $s n-1$ and $s n-3$ position are dissimilar then 1,3 DAG is chiral. Since in many studies neither fatty ester species nor their respective position on the 1,3 DAG molecule have been determined we refer to 1,3 DAG as racemic/rac-1,3 DAG throughout this review to account for unknown stereochemistry. Furthermore, enantiomeric DAGs can be classified in respect to the R/S-configuration nomenclature based on the Cahn- 


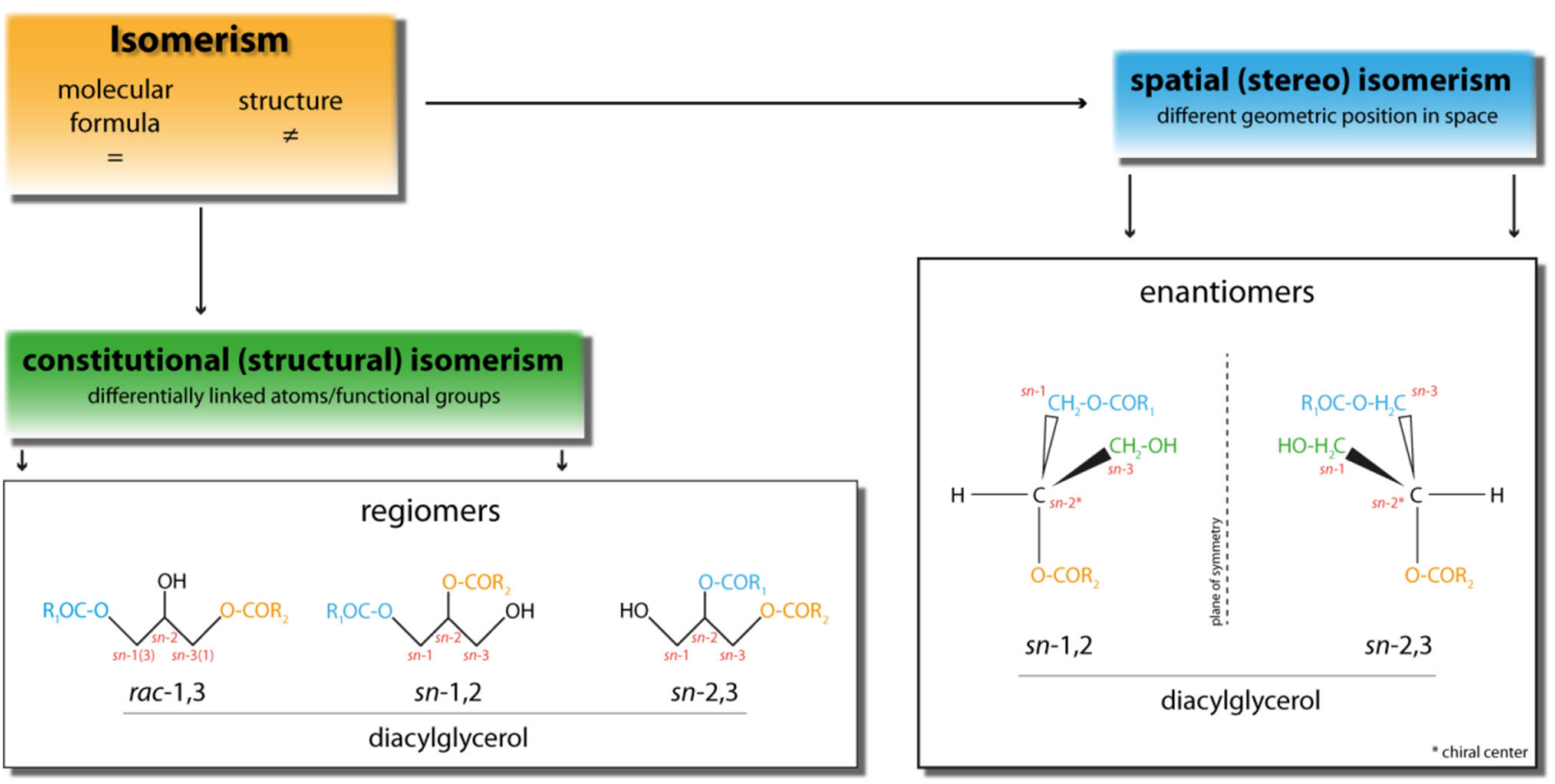

Fig. 1 Schematic depiction of the different forms of isomerism of diacylglycerol. Diacylglycerols feature different forms of isomerism and can differ either in constitutional (structural) or spatial (stereo) conformation. For detailed explanation see text

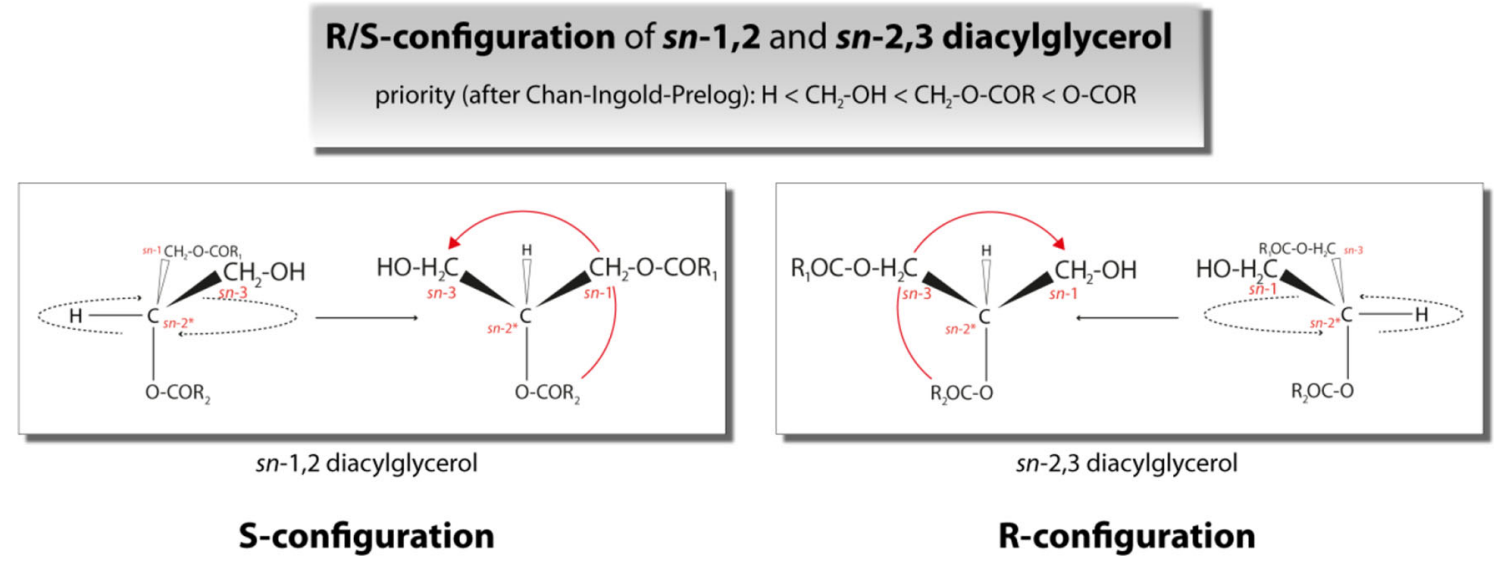

Fig. 2 R/S nomenclature of diacylglycerol (DAG) enantiomers according to Cahn-Ingold-Prelog convention. $s n-1,2$ DAG represents the S-configuration whereas $s n-2,3$ DAG represents the R-configuration

Ingold-Prelog (CIP) system. The CIP system is used to uniquely specify enantiomers. Therefore, priorities are assigned to all groups attached to the chiral center (CIP rules) $[1,2]$. Subsequently, the lowest ranked group is set below the image plane and the other groups are counted starting at highest priority substituents. The counted sequence can be either clockwise or counterclockwise and specifies the present molecule as either R-configured (from Latin: rectus-right) or S-configured (from Latin: sinister-left). In case of DAG, $s n-1,2$ DAG reflects the S-configuration whereas $s n-2,3$ DAG is R-configured (Fig. 2).
Upon hydrolysis of the sn-2-bound FA of a TAG molecule, the generated DAG exhibits rac-1,3 conformation. In regard to the different region of hydrolysis ( $s n-1 /$ $s n-3$ : esters of a primary alcohol; sn-2: ester of a secondary alcohol), rac-1,3 DAG is a so-called regiomer (Fig. 1). Thus, lipases can regioselectively differentiate between $s n$ 2 and $s n-1 / s n-3$ position or enantioselectively differentiate between $s n-1$ and $s n-3$ position. Similarly, other DAG metabolizing enzymes, such as acyltransferases may also discriminate between different isoforms of DAGs.

These differences in DAG isomerisms as well as in the selectively of DAG-generating/consuming enzymes are an 
important issue when DAGs which represent an intersection point between lipid and signaling metabolism are investigated. The selectivity of cellular lipases/acyltransferases as well as the impact of DAG isomerism on cellular metabolism is important to fully understand cellular functions of different DAG molecules.

\section{Intracellular formation of DAG}

Intracellularly, several reactions contribute to the generation of DAG and are located at different subcellular compartments, including the endoplasmic reticulum (ER), the Golgi network, lipid droplets (LDs), and the plasma membrane. Therefore, either TAG, stored in cytoplasmic or ER-associated LDs or PLs, which are building blocks of cellular membranes, can act as source for lipase-, or acyltransferase-dependent generation of DAG. Additionally, DAGs are also an intermediate during de novo synthesis of TAGs either generated by acyltransferases or by phosphohydrolases. The stereo/regioselectivity of involved enzymes and the isomerism of formed DAGs are largely unknown but might be crucial for subsequent cellular reactions. The following sections describe known biochemical characteristics and stereo/regiochemical properties of enzymes involved in the formation of DAGs (Fig. 3).

\section{Formation of DAG by neutral triglyceride lipases}

Within most cell types, TAG turnover is crucial to balance energy storage and utilization. In whole body energy metabolism of higher organisms, this function is mainly achieved by specialized cells, named adipocytes and hepatocytes, constituents of the white adipose tissue (WAT) and the liver, respectively. In adipocytes, excessive energy is stored in form of TAG in cytoplasmic LDs. Interestingly, adipocytes usually harbor one giant $\mathrm{LD}$ with a size range of about $100 \mu \mathrm{m}$, while non-adipocytes exhibit multiple LDs with a diameter of around $1 \mu \mathrm{m}$. Irrespectively thereof, all LDs share basically the same architecture. The core is strictly assembled by hydrophobic lipid esters, like TAG and cholesteryl esters (CEs), and the surface is formed by a PL monolayer [3]. This monolayer harbors a variety of anchored or embedded proteins and serves as an amphipathic shield against the aqueous milieu present within the cell [4]. The most important function of adipocyte LDs is the storage and the lipase-dependent release of energy metabolites, primarily in form of FAs. This tightly regulated process of TAG degradation, known as lipolysis, is initiated by TAG lipases that generate DAGs and FAs.

Hepatocytes are a crucial intersection of the energy metabolism by receiving, remodeling, and distributing lipids from and to the systemic circulation. Hepatocytes incorporate circulating FAs into TAGs which are stored either in cytoplasmic LDs or used for very low density lipoprotein synthesis within the lumen of the endoplasmic reticulum (ER) [5]. Both, the cytoplasmic and the luminal TAG stores are accessible for different lipases.

\section{Adipose triglyceride lipase generates rac-1,3 DAG at the $L D$}

In 2004, adipose triglyceride lipase (ATGL) was independently identified by three laboratories. The former denoted transport secretion protein 2.2 was renamed as ATGL/patatin-

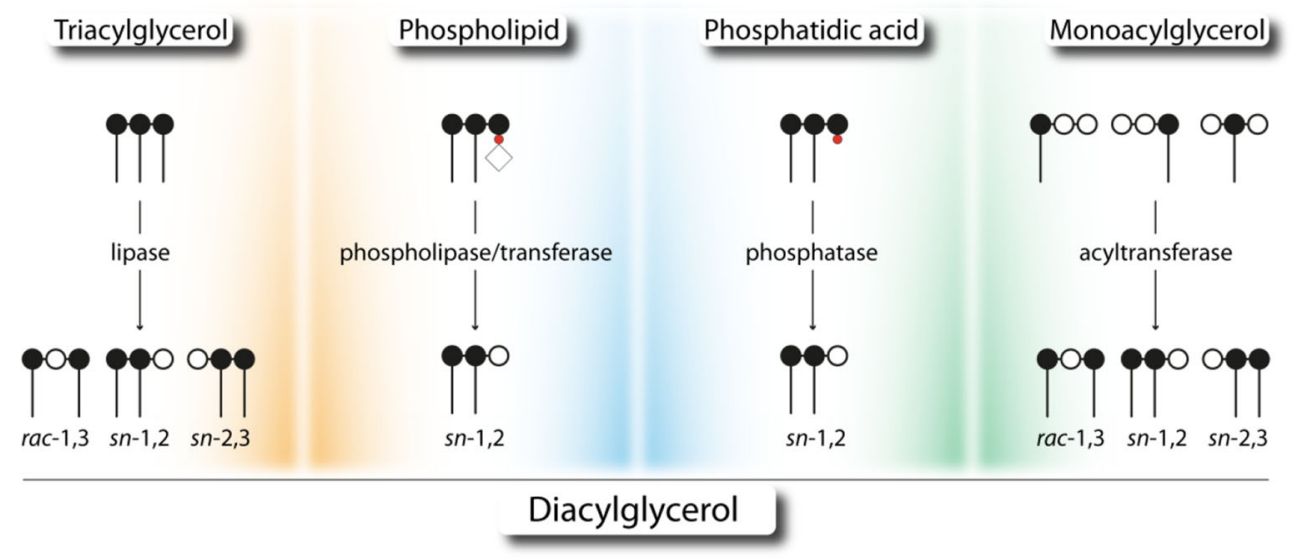

Fig. 3 Catabolic and anabolic reactions leading to the formation of diacylglycerol. Different stereo/regioisomers of diacylglycerols are generated by the hydrolysis of either triacylglycerol (lipase) or phospholipids (phospholipase), and are product of sphingomyelin synthesis (transferase reaction). Furthermore, diacylglycerol is the product of the dephosphorylation of phosphatidic acid (phosphatase) and of the esterification of monoacylglycerol by acyltransferases. Carbon atoms of the glycerol backbone are depicted as filled (esterified) or open (unesterified) circles. Phosphate group, phosphate head group, and fatty acids are depicted as red circle, open rhomb, and dash, respectively 
like phospholipase domain containing 2 (PNPLA2) [6], desnutrin [7], and calcium-independent phospholipase A2 $\zeta$

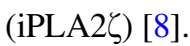

ATGL is one of nine PNPLA family members found in humans (PNPLA1-9) [9]. The PNPLA protein family is named after the patatin-domain which was first identified in hydrolases of the potato plant and denominated after the most abundant protein of the potato tuber, patatin. Lipid hydrolases, containing this domain, catalyze the non-selective hydrolysis of a variety of lipids, including PLs, glycolipids, DAGs, and monoacylglycerols (MAGs) [10, 11]. Orthologs of ATGL exist in almost every eukaryotic species including invertebrates, fungi, and plants.

ATGL localizes to cytosolic LDs [12] and exhibits highest hydrolytic activity for TAGs, much less for retinyl esters (REs) and no detectable activity for other neutral lipids such as DAGs, MAGs, and CEs [6, 13]. Additionally, phospholipase A2 (PLA2) activity as well as DAG transacylase activity have been also reported but the physiological relevance of these activities has not been established [8, 14].

In mice, ATGL mRNA is expressed in all examined tissues. Highest expression is observed in WAT and brown adipose tissue (BAT) and is manifold increased upon fasting. Lower expression levels are detectable in skeletal muscle, cardiac muscle, liver, and testis $[6,7,15$, 16]. Interestingly, besides nutritional regulation at the mRNA level $[6,7,17,18]$ ATGL's activity is highly regulated at the post-transcriptional level by the interaction with an activator and inhibitor protein $[19,20]$. Binding of molar amounts of comparative gene identification-58 (CGI-58; or $\alpha / \beta$ hydrolase fold domain containing protein 5, ABHD5) stimulates ATGL's activity up to 20-fold [19, 21]. In contrast, binding of molar amounts of $\mathrm{G}_{0} / \mathrm{G}_{1}$ switch gene 2 (G0S2) to ATGL complete abolishes ATGL's hydrolase activity [20, 21]. Interestingly, CGI-58 and G0S2 regulate ATGL in a noncompetitive manner, although the molecular mechanism behind CGI-58- and G0S2-dependent regulation of ATGL's activity is unknown.

The key role of ATGL in the degradation of TAGs is evident by the phenotype of ATGL-deficient mice. ATGL knockout mice exhibit enlarged adipose tissues. TAG accumulation in LDs is observable in all tissues, reaching up to tenfold increase in TAG content [22]. These observations consolidate ATGL as the rate limiting lipase in cytoplasmic TAG mobilization of adipose and non-adipose tissues.

Studies on substrate and stereospecificity revealed that ATGL hydrolyzes long-chain fatty acids of various length and saturation. Importantly, ATGL is unique among mammalian lipases by hydrolyzing TAGs selectively at $s n$ 2 position. In the absence of its co-activator protein CGI-
58, ATGL generates rac-1,3 DAGs. Interestingly, upon coactivation by CGI-58, ATGL expands its regioselectivity to the $s n-1$ position, generating additionally $s n-2,3$ DAGs. Notably, ATGL does not hydrolyze ester bonds at the $s n-3$ position of TAGs, hence does not generate detectable amounts of $s n-1,2$ DAGs [23].

\section{Hormone-sensitive lipase hydrolyzes lipolysis-derived DAGs at the sn-3 position}

Hormone-sensitive lipase (HSL) was initially identified following up the observation that WAT lipolysis is strongly inducible by hormones [24, 25]. HSL is expressed in many tissues; protein as well as mRNA expression of HSL are highest in WAT and BAT. Expression levels are barely increased upon fasting suggesting that its activity is largely regulated by post-translational events $[26,27]$. The $\mathrm{COOH}$ terminus of HSL harbors an $\alpha / \beta$ hydrolase fold domain, containing an active site serine $\left(\mathrm{Ser}^{423}\right)$ as part of a catalytic triad $\left(\mathrm{Asp}^{703}, \mathrm{His}^{733}\right)$, responsible for hydrolytic activity [28-31]. The lipid-binding site as well as the site responsible for protein dimerization is located at the $\mathrm{NH}_{2}-$ terminal region of HSL [32].

HSL-dependent activity is strongly regulated by hormones. A variety of phosphorylation events controls HSL activity by affecting both intracellular localization and protein-protein interactions. The major positive stimulus is caused by catecholamines which bind to $\beta$-adrenergic receptors during periods of nutritional deprivation (fasting). The contrary nutritional condition (feeding) inhibits HSL activity via insulin [33-39]. Even though phosphorylation events of HSL are crucial, they cause only moderate changes in enzymatic activity ( $\sim$ twofold). The more important factor in HSL activation is the translocation of the enzyme from the cytosol to the LD. In adipocytes, LDs are shielded by perilipin-1 which surrounds LDs, forming a barrier between lipases and respective substrates and prevents effective lipolysis [40, 41]. Upon $\beta$-adrenergic stimulation perilipin-1 is phosphorylated [42-45] which causes HSL to bind to perilipin1. Thereby, HSL translocates to the LD surface and deploys full activity [46, 47].

The long-standing dogma that HSL acts as pacemaker of lipolysis, thereby hydrolyzing TAGs and DAGs, was disproven when mice, carrying a global deletion of HSL, showed no signs of obesity on a high-fat diet but exhibited normal bodyweight and even reduced fat mass [48, 49]. Decreased adipose mass was partially explained by reduced FA esterification, counteracting decreased lipolytic activity [50]. Noteworthy, HSL-deficient adipocytes remain catecholamine-inducible and exhibit increased FA release indicating that an additional TAG lipase must exist $[48,51,52]$. However, the most intriguing finding in HSL 
knockout mice was the drastic accumulation of DAG in several tissues suggesting that HSL is responsible for DAG hydrolysis [51].

Remarkably, HSL exhibits a uniquely broad substrate spectrum which includes TAGs, DAGs, MAGs, CEs, REs, and the artificial water-soluble esters of para-nitrophenol [25, 53-55]. However, in vitro studies demonstrated that the specific activity of HSL is highest against DAG which exceeds those against TAG and MAG around tenfold [53, 56]. Earlier studies reported specificity of HSL for $s n-1 /(3)$ DAGs [56], whereas most recently HSL was identified to be $s n-3$ specific [57]. Concerning substrate specificity, HSL exhibits preference for polyunsaturated FAs $(n-3 / n-6)$ [58].

Both ATGL and HSL together are responsible for more than $90 \%$ of lipolytic (TAG hydrolase) activity as determined in cultured adipocytes and murine WAT [59]. This suggests that other lipases may contribute to a minor extent to TAG breakdown in adipose tissue. Several other enzymes which are known to catabolize TAG breakdown are discussed below.

\section{Triacylglycerol hydrolase/carboxylesterase-3 hydrolyzes short-chain TAGs at the ER}

Triacylglycerol hydrolase/carboxylesterase-3 (TGH/Ces3) was initially purified from porcine liver and contains an $\alpha / \beta$ hydrolase fold common for lipases. Additionally, the $\mathrm{NH}_{2}$ terminal region shows high similarity to that of proline- $\beta$ naphthylamidase which is a member of the carboxylesterase family $[60,61]$. Additional structural characteristics are an $\mathrm{NH}_{2}$-terminal-located ER signal peptide, a COOH-terminal ER-retention signal (HXEL), a predicted catalytic triad formed by $\mathrm{Ser}^{221}, \mathrm{Glu}^{353}$ (354) and $\mathrm{His}^{466}{ }^{(468)}$, and a hydrophobic stretch (AA 414-429) possibly involved in lipid binding [62-68]. In contrast to ATGL and HSL, TGH/Ces3 is mainly expressed in liver and to a low extent in WAT, kidney, cardiac muscle, and small intestine [66]. TGH/Ces3 mRNA level, protein expression, and concomitant hepatic microsomal esterase activity are decreased upon treatment with glucocorticoid analogs, mainly through destabilization of mRNA [69].

Intracellularly, TGH/Ces3 localizes to the ER, especially to areas surrounding cytosolic LDs [70]. TGH/Ces3 catalyzes the hydrolysis of long-, medium-, and preferentially short-chained TAGs [60] with so far unknown stereo/regioselectivity. Besides an unclear role in adipocytes, TGH/Ces3 is affirmed to be involved in the mobilization of hepatic TAG stores, required for the assembly of apoB100-lipoproteins, which has been deduced from the phenotype of mice carrying global disruption of $T G H / C e s 3$ gene [71].
DDHD domain containing 2 hydrolyzes TAGs in the brain

DDHD domain containing 2 (DDHD2), formerly known as KIAA0725p, is one of three sequence-related serine hydrolases which have been annotated as $s n-1$ specific phospholipases [72]. Mutations in DDHD2 are causative for the genetic disorder known as complex hereditary spastic paraplegia and cause intellectual disability, lower limb spasticity, and weakness.

The $\sim 80 \mathrm{kDa}$ large protein DDHD2 is ubiquitously expressed and exhibits highest expression levels in brain and adipose tissues. Within the cell, DDHD2 localizes to the Golgi network and exhibits phospholipase A1 (PLA1) activity against various PL substrates, including phosphatidic acid (PA), phosphatidylserine (PS), phosphatidylcholine (PC), and phosphatidylethanolamine (PE) [72]. However, a recent study identifies DDHD2 as intracellular TAG lipase involved in neutral lipid metabolism of the central nervous system [73]. DDHD2-deficient mice show significantly elevated TAG levels in brain, especially neurons, but not in other peripheral tissues. Similar, TAG accumulation pattern was observed using a selective DDHD2 inhibitor. Unexpectedly, no changes in the amount or composition of brain PLs were detected in DDHD2deficient mice [73]. The stereo/region-selectivity of DDHD2 has not been investigated. However, since DDHD2 exhibits PLA1 activity, in addition to its TAG hydrolase activity, DDHD2 may hydrolyze TAG at the $s n$ 1 position, generating $s n-2,3 \mathrm{DAG}$.

\section{Other intracellular triglyceride lipases}

Several members of the PNPLA protein family, like adiponutrin (PNPLA3), GS2 (genes sequence 2, also annotated as PNPLA4), GS2-like (PNPLA5) as well as triacylglycerol hydrolase 2/carboxylesterase ML1 (TGH2), have been reported to possess TAG hydrolase activity in vitro and thus may be involved in cellular TAG catabolism.

TGH2 mRNA is highly expressed in WAT, BAT, and liver, and mRNA expression in adipocytes is induced upon differentiation [74]. A substantial amount of TGH2 protein localizes to LDs but $\mathrm{TGH} 2$ is also found in cytoplasmic and microsomal fractions. TGH2 shares around $70 \%$ identity to murine TGH/Ces3 and contains a catalytic triad $\left(\mathrm{Ser}^{221}, \mathrm{Glu}^{353}\right.$, His ${ }^{466}$ numbered for the murine protein), a hydrophobic stretch (414-429 AA), possibly involved in lipid binding, as well as a potential COOH-terminal ER retrieval sequence (HXEL) [74]. TGH2 exhibits hydrolytic activity for para-nitrophenyl butyrate, TAGs, and MAGs but no activity for DAGs, CEs, or PLs [74]. Analyses of FA- and glycerol release of isoproterenol-stimulated 3T3- 
L1 cells, infected with an adenovirus expressing TGH2, suggested a minor contribution $(\sim 20 \%)$ of $\mathrm{TGH} 2$ to cellular lipolysis [74]. Besides the discovery that TGH2 prefers short-chained TAGs as substrates, nothing is known about the stereo-/regioselectivity of this enzyme.

Human GS2 gene which has homologues in several mammalian genomes, except the mouse, is expressed in several tissues including WAT, skeletal muscle, cardiac muscle, liver, and skin (keratinocytes) [9, 14, 15, 75]. GS2 exhibits high homology to ATGL and contains an $\mathrm{NH}_{2}-$ terminal-located catalytic dyad, including the canonical GXSXG lipase motif [14]. A variety of substrates is described for human GS2, including TAGs [14, 15], REs [14, 76], and PLs. Additionally, also a neutral lipid transacylase activity has been reported [8, 14]. Interestingly, the GS2 orthologue in rat displays lower RE hydrolase activity as well as differences in TAG hydrolase activity [14]. Whereas nothing is known about the FA preference, human GS2 is reported to hydrolyze TAGs at $s n-1 /(3)$ and $s n-2$ position, generating $r a c-1,3$ and $s n-1,2 /$ $(2,3)$ DAGs [14]. These products are not observable for rat GS2 which generates only $s n-1,2 /(2,3)$ DAGs. However, the physiological role of GS2 is unclear since no knockout model has been described and knockout mice cannot be generated (the mouse genome lacks the GS2 gene).

In contrast to GS2, GS2-like (also annotated as PNPLA5) mRNA is expressed to a low level in both mouse and human WAT, BAT, brain, and lung [9, 15]. The murine mRNA is upregulated during adipocyte differentiation and highly induced in liver samples of leptin-deficient mice [15]. In contrast, mRNA expression is markedly decreased during fasting [15]. Hydrolytic activity of GS2like emerges to be enigmatic since non-tagged GS2-like protein exhibits no RE or TAG hydrolase activity in vitro [14] but lowers TAG accumulation when expressed in cells [15]. The stereo-/regioselectivity and the physiological relevance of GS2-like are unknown.

Adiponutrin (also annotated as PNPLA3) was first described as adipose tissue-specific transcript strongly regulated by the nutritional state [77]. Within the PNPLA family, adiponutrin shares highest sequence homology with ATGL. Adiponutrin, like all PNPLA proteins, contains a canonical serine lipase motif (GXSXG) within a catalytic dyad [10]. Adiponutrin is highly expressed in WAT, skin, and liver, and localizes to intracellular membranes and LDs [78, 79]. mRNA levels are highly increased by insulin or during adipocyte differentiation and are strongly decreased upon fasting (which is the opposite to ATGL mRNA expression) [7-9, 15, 77, 80]. Human adiponutrin exhibits TAG, DAG, MAG, and RE hydrolase as well as transacylase and PLA2 activity in vitro [8, 10, 15, 81]. Adiponutrin preferentially hydrolyzes TAG species containing long-chain unsaturated FAs (C18:1) thereby generating $s n-1,2 / 2,3$ DAGs (DAG species were not analyzed) [82]. However, overexpression or knock down of adiponutrin in mice did not affect hepatic TAG levels [8385]. Notably, a human adiponutrin mutant (I148M) has been found to be strongly associated with nonalcoholic fatty liver disease and overexpression of the I148M mutant or a I148M knock-in in mice causes steatosis [84, 86]. In contrast to the reported hydrolytic activities, a recent study found that human and murine adiponutrin act as nutritionally regulated acyl-CoA-dependent lysophosphatidic acid acyltransferase and that this activity is elevated in the I148M mutant proteins [87]. Since decreased TAG hydrolytic activity as well as increased lysophosphatidic acid acyltransferase activity of the I148M mutant could explain the development of liver steatosis in humans, further studies are needed to clarify the physiological role of this protein.

\section{Phospholipase C generates $s n-1,2$ DAGs at the plasma membrane}

Phospholipases specifically hydrolyze PLs at different chemical positions. The four major classes of phospholipases are distinguished by the type of catalyzed reaction. PLA1 and PLA2 catalyze the hydrolytic cleavage of the acyl chains at respective $s n-1$ or $s n-2$ position. In contrast, phospholipase C (PLC) and D (PLD) cleave phosphoglycerol and phospho-headgroup esters, respectively. Hence, only PLCs contribute directly to the intracellular formation of DAG from glycerophospholipids.

PLC activities have been grouped according to their substrate preference into phosphatidylcholine- and phosphatidylinositol-specific PLCs. Phosphatidylcholinespecific PLC (PC-PLC) are described in many organisms including mammals, in which the number of PC-PLC isoforms depends on cell type and species [88]. Localization and activity studies in murine fibroblasts as well as human lymphocytes showed PC-PLC expression and activity at perinuclear areas and upon mitogen-mediated cell receptor stimulation a translocation to the outer leaflet of the plasma membrane [89]. The fact that the gene sequence of mammalian PC-PLC has not been identified so far displays a critical hindrance since overexpression or deletion studies of mammalian PC-PLC cannot be performed. Thus, relatively little is known about the physiological role of mammalian PC-PLCs.

So far, thirteen phosphatidylinositol-specific PLC (PIPLC) isozymes have been identified and assigned to six subclasses, namely $\beta 1-4, \gamma 1-2, \delta 1, \delta 3-4, \varepsilon, \zeta$, and $\eta 1-2$ [90-93]. Virtually all PI-PLC isozymes are highly expressed in different brain regions and only a few $(\beta 3, \delta 1$, $\delta 3, \delta 4, \varepsilon)$ are distributed among other peripheral tissues like liver, skeletal muscle or cardiac muscle [94]. 
Intracellularly, the soluble PI-PLC proteins are localized mainly in the cytoplasm. Upon cell activation PI-PLCs translocate to the plasma membrane and develop catalytic activity [94]. The PI-PLC-dependent hydrolysis of phosphatidylinositol 4,5-bisphosphate (PIP2), a plasma membrane-associated PL, describes a key event during regulation of a variety of cellular functions. By producing two intracellular messengers, namely $s n-1,2$ DAG and inositol 1,4,5-triphosphate $\left(\mathrm{IP}_{3}\right)$, this reaction mediates activation of protein kinase $\mathrm{C}$ (PKC) as well as intracellular $\mathrm{Ca}^{2+}$ release, respectively [94]. Due to the $s n-3$ position of the phosphate residue of PLs, PI-PLC generates exclusively $s n$-1,2 DAGs [23].

\section{Sphingomyelin synthase generates $s n-1,2$ DAGs at the ER and the plasma membrane}

Sphingomyelin synthases (SMSs) catalyze the transfer of the phosphorylcholine residue from PC to a ceramide backbone thereby generating sphingomyelin (SM) and $s n-1,2$ DAG $[95,96]$. So far, two mammalian enzymes, SMS1 and SMS2 have been described [97, 98]. SMS1 localizes exclusively to the luminal side of the trans-Golgi whereas SMS2 additionally localizes to the extracellular leaflet of the plasma membrane [97, 99]. DAGs, produced by SMS1/2 at the trans-Golgi, may trigger the translocation of protein kinase $\mathrm{D}(\mathrm{PKD})$ which catalyzes the formation of secretory vesicles [100, 101]. In contrast, DAGs generated at the plasma membrane are most likely utilized by SMS2 to restock SM levels which are locally reduced by sphingomyelinases [102]. SMS-related protein (SMSr) was recently identified as third member of the SMS clan. SMSr localizes to the ER and converts ceramides, generated at the ER, to ceramidephosphoethanolamine (CPE) using PE as donor [97, 103]. However, the CPE synthesis rate is very low as compared to those of SM synthesis. Thus, SMSr is supposed to regulate ceramide concentrations at the ER [103]. Substrate specificity studies including all three enzymes showed that SMS1 and SMSr are monofunctional SM and CPE synthases, respectively, whereas SMS2 is a bifunctional enzyme, able to catalyze both, SM and CPE synthesis [104]. All three enzymes are ubiquitously expressed in mammals and regulators of SM and ceramide homeostasis. Although the SMS family members exhibit a diverse substrate specificity, the fact that these enzymes use PLs as donors, suggests that the resulting DAG intermediates are $s n-1,2$ isomers.

\section{Synthesis of DAG de novo or by MGAT reaction}

In addition to the catabolic generation of DAGs, two pathways contribute to the anabolic generation of DAGs. In those pathways DAG arises as intermediates of the de novo biosynthesis of TAGs and PLs. The G3P pathway is the major pathway of TAG synthesis in most tissues, predominantly in liver and WAT. The G3P-pathway involves the consecutive acylation of G3P, catalyzed by acyl-CoAdependent glycerol-3-phosphate acyltransferase (GPAT) and acyl-CoA acylglycerol-3-phosphate acyltransferase (AGPAT). The product of these reactions is PA which is dephosphorylated to DAG by PA phosphatase (PAPase, lipins) [105-107]. Since G3P is utilized in this biosynthesis, these DAG isomers have exclusively the $s n-1,2$ conformation [108, 109]. In the other so-called MAGpathway, $s n-2$ MAGs and long-chain fatty acyl-CoAs are esterified to $s n-1,2$ DAG by monoacylglycerol-acyltransferase (MGAT) [110]. This pathway plays a predominant role in enterocytes upon feeding and is also involved in the storage of TAGs in adipocytes [111, 112].

\section{sn-1,2 DAG is generated in the G3P pathway at the ER}

More than 50 years ago, it was discovered that the liver exhibits enzymatic activity that generates PA from glycerol and that DAG is a precursor for both PL and TAG biosynthesis. In fact, in the late 1950s, Kennedy and coworkers described an enzymatic activity that dephosphorylates PA to form DAG in vitro [113]. This finding completed the enzymatic sequence of TAG and PL synthesis from glycerol and is since then known as the Kennedy pathway [114, 115].

In mammals, PA dephosphorylation (3-sn-phosphatidate phosphatase/phosphohydrolase, PAP/lipin) is catalyzed by three recently identified members of the lipin family, namely lipin1, 2 and 3. Among these, lipin1 is the most extensively studied. It is highly expressed in tissues with high rates of lipid flux, like cardiac muscle, WAT, and skeletal muscle [116, 117]. In WAT and skeletal muscle, lipin1 accounts for the entire PAP activity, whereas the other two members contribute essentially to total PA dephosphorylation of liver, brain, and placenta [117, 118]. Early studies revealed that lipins locate within the cytoplasm and translocate rapidly to ER membranes upon elevated levels of intracellular FAs [119]. Loss-of-function mutations within lipin1 cause dramatic metabolic impairments, like hypertriglyceridemia and severe hepatic steatosis, as observed in fatty liver dystrophic mice [116]. The opposite effect is observed in transgenic mice overexpressing lipin1 in adipocytes. These mice exhibit increased amounts of TAG which fits to lipin1-dependent generation of DAGs as precursor for TAGs [120]. Since G3P and thus also PA are phosphorylated at $s n-3$ position of the glycerol backbone, their dephosphorylation generates exclusively $s n-1,2$ DAGs. 
The MGAT reaction generates sn-1,2/2,3 DAGs at the ER in the digestive tract

MGAT enzymes catalyze the esterification of MAGs, which constitutes the first step in TAG synthesis following dietary absorption by enterocytes. So far, three enzymes are known to possess MGAT activity, MGAT1, -2, and -3. All three isoforms are located at the ER [121-125]. Besides similar intracellular localization, MGAT isoforms differ in their tissue-specific expression pattern and in their specific catalytic activities. In contrast to MGAT1 which is mainly expressed in stomach, adipose tissues, and kidney, MGAT2 and MGAT3 exhibit highest expression in small intestine [121-123, 125, 126]. MGAT3 is found exclusively in higher mammals and exhibits significantly higher specific DAGacyltransferase activity as compared to MGAT1 and MGAT2. This indicates that MGAT3 functions as TAG synthase [127]. Furthermore, MGAT3 prefers sn-2 MAG as acyl acceptor and activated palmitic acid (C16:0) and C18:1 as acyl donors [123]. Thus, generated DAG species exhibit either $s n-1,2$ or $s n-2,3$ isomerism. The prior-mentioned lipids, sn-2 MAG, C16:0, and C18:1, are the major hydrolytic products of pancreatic triglyceride lipase/colipase (PTL)-dependent TAG hydrolysis during intestinal digestion [128, 129]. Hence, MGAT3 is thought to be main enzyme involved in the re-esterification of dietary absorbed fat within the small intestine.

MGAT2 was found to exhibit little or no selectivity concerning chain-length or level of saturation of activated FAs (FA-CoAs) [121]. Furthermore, incubation of MGAT2 with $\mathrm{rac}-1 / 3$ MAGs results in the generation of $\mathrm{rac}-1,3$ and rac-1,2/2,3 DAGs, implicating that all positions of the glycerol backbone can be esterified by MGAT2 [121]. In contrast, MGAT1 displays a stricter selectivity for glycerol position as well as for utilized FA-CoA species. MGAT1 shows high activity when incubated with long-chain unsaturated FA-CoAs, the highest with activated arachidonic acid (C20:4) [122]. Incubation with either $s n-1$ or $s n$ 3 MAGs leads to the generation of $r a c-1,3$ DAGs indicating that MGAT1 preferentially esterifies $s n-1$ or $s n-3$ position [122]. In line with these findings, incubation of $s n$ 2 MAGs results exclusively in the generation of the rac1,2/2,3 DAGs [122].

\section{Extracellular formation of DAGs}

Diacylglycerols are also intermediates of the extracellular lipid metabolism. DAGs are generated in the process of food digestion as a result of TAG hydrolysis by specific lipases. Additionally, DAGs are generated in the circulation by the hydrolysis of lipoprotein-associated TAGs, by the action of lipoprotein lipase (LPL) and hepatic lipase (HL). Interestingly, all stereochemically characterized TAG lipases involved in lipid digestion, such as lingual lipase (LL), PTL, and gastric lipase (GL) exhibit preference for $s n-1$ or $s n-3$ position of TAGs. The specificity of pancreatic lipase-related proteins 1 and 2 (PLRP1/2) has so far not been determined. Furthermore, only PLRP2 but not PLRP1 is catalytically active against TAG [130-133]. PTL, GL, and LL hydrolyze TAG specifically at the $s n-3$ position but also hydrolyze DAGs. Thus, they break down TAGs into FAs and sn-2 MAGs [129, 134-137]. An example for a positional unspecific lipase is bile salt-stimulated lipase (BSSL, =carboxyl ester lipase, CEL) which hydrolyzes all positions of TAGs, generating free glycerol and FAs [138]. In contrast to the intestinal lipases, LPL and HL which deplete circulating lipoproteins from TAGs, exhibit $s n-1$ specificity for TAG and also hydrolyze DAGs at the $s n-2$ and $s n-3$ position, generating either $s n-3$ or $s n-2$ MAGs, respectively [134, 135, $139,140]$. Since the majority of these lipases not only generates but also accepts DAG as further substrate, the short half-life of extracellular DAGs makes them unlikely to be involved in intracellular signaling events. However, at least in the intestine the absorbed $s n-2$ MAG has signaling potential, since $s n-2$ arachidonoyl glycerol (2-AG) is an endogenous ligand of the cannabinoid receptors 1 and 2 (CB1/2) [141, 142]. 2-AG is known to retrogradely bind and activate $\mathrm{CB} 1 / 2$. Furthermore, recent evidence has shown that in the intestinum, 2-AG inhibits gut motility and propulsion [143-145].

\section{Intracellular metabolization of DAGs}

The intracellular metabolization of DAGs involves different enzymes, which in part exhibit selectivity for specific DAG isoforms. Thus, isomerism of DAG may influence (1) its degradation by lipases which leads to different regiomers of MAG species, (2) its re-esterification to TAG by DAG-specific acyltransferases, (3) its conversion to PC by CDP-choline:1,2-diacylglycerol choline phosphotransferases (CPTs), and (4) its phosphorylation by diacylglycerol kinases (DGKs) (Fig. 4).

\section{Diacylglycerol acyltransferases are distinct in intracellular localization and enzymatic preference}

The acylation of DAG is the final step of TAG synthesis. This esterification reaction uses FA-CoA as acyl donor and DAG as acyl acceptor and is catalyzed by enzymes called diacylglycerol- $O$-acyltransferases (DGATs). So far, two mammalian DGAT enzymes have been identified, named DGAT1 and DGAT2.

DGAT1 was initially identified due to its high sequence similarity with acyl-CoA:cholesterol acyltransferase 


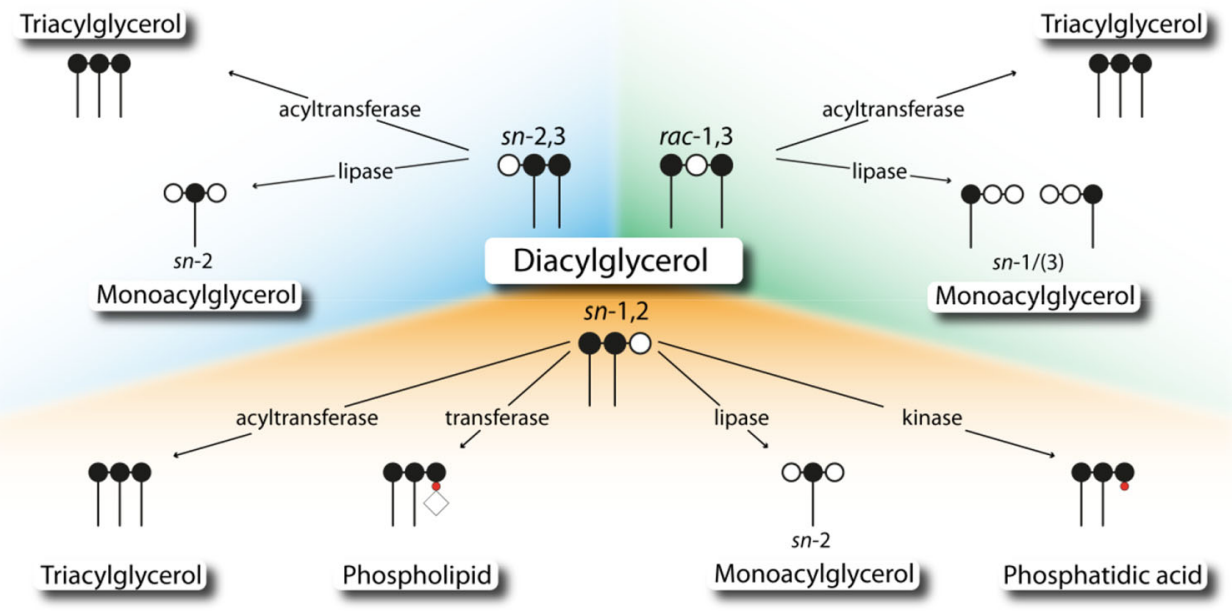

Fig. 4 Intracellular enzyme classes involved in diacylglycerol utilization. Different isoforms of diacylglycerol display substrates for several enzyme classes, including transferases, kinases, and lipases. Carbon atoms of the glycerol backbone are depicted as filled

(ACAT) enzymes [146]. DGAT1 belongs to the large family of membrane-bound $O$-acyltransferases whose members catalyze the transfer of FAs onto thiol or hydroxyl groups of either lipid or protein acceptors [147]. DGAT1 mRNA is highly expressed in the small intestine, adipose tissues, skeletal muscle, cardiac muscle, skin, spleen, and testis, where it localizes strictly to ER membranes [127, 148, 149]. DGAT1 contains three transmembrane-spanning domains and an active site within the COOH-terminal region, facing the ER lumen [150]. Mutagenesis of a highly conserved histidine residue (His426) located within the $\mathrm{COOH}$-terminal region and supposed to be part of the active site abolishes the ability of DGAT1 to synthesize TAG in vitro [150]. The $\mathrm{NH}_{2}$-terminal region is located in the cytoplasm, facilitates the formation of tetramers, and binds long-chain FA-CoAs $[150,151]$. Noteworthy, a C-terminal deletion of DGAT1 is inactive and does not act as a dominant negative protein [152]. The fact that microsomal preparations exhibit an "overt" (cytoplasmic) and a "latent" (luminal) DGAT activity [153], both influenced by pharmacological DGAT1 inhibition in vitro or genetically deletion of DGAT1 [154], questions whether the active site of DGAT1 is entirely oriented to the lumenal side of the ER membrane. In addition to the synthesis of TAG, DGAT1 catalyzes a diversity of different acyltransferase reactions, including MGAT, wax monoester synthase, and retinol acyltransferase [155].

DGAT2 shares little similarity with DGAT1. It belongs to a seven-member family including above-mentioned MGAT1, -2 , and $-3[124,156]$. All members of this family contain the highly conserved amino acid sequence HPHG, (esterified) or open (unesterified) circles. Phosphate group, phosphate head group, and fatty acids are depicted as red circle, open rhomb, and dash, respectively

which in case of DGAT2 is thought to be part of the active site [124, 147, 157]. Additionally, DGAT2 contains a FLXLXXXn consensus sequence which functions as a neutral lipid-binding domain, also found in other neutral lipid metabolizing proteins, such as plasma cholesteryl ester transfer protein, HSL, or TGH/Ces3 [62, 157, 158]. Mutation studies on DGAT2 demonstrated that this neutral lipid-binding domain of DGAT2 is responsible for DAG binding, since DGAT2 variants with mutations in this region exhibit reduced activities [157]. Expression of DGAT2 mRNA is highest in liver, adipose tissues, mammary glands, testis, peripheral leukocytes, and cardiac muscle [124]. In cultured cells DGAT2 localizes to the ER. Upon supplementation of cells with FAs, known to induce TAG synthesis, DGAT2 also localizes to mitochondriaassociated membranes (ER domains tightly interacting with mitochondria) and to LDs $[149,159]$. Unlike DGAT1, DGAT2 contains two ER-spanning domains and both, the $\mathrm{COOH}$ - as well as $\mathrm{NH}_{2}$-terminal domain, face the cytoplasm [157]. Hence, DGAT2 is in part responsible for the "overt" DGAT activity detectable in cells. Additionally, the C-terminus of DGAT2 is supposed to be involved in directing the enzyme to LDs, since DGAT2 with a truncated or mutated C-terminus fails to co-localize with LDs [160]. These different orientations of the active site of DGAT enzymes suggest a spatial separation of DGAT1 and DGAT2-dependent TAG synthesis. Furthermore, and in contrast to DGAT1, DGAT2 does not exhibit activities towards substrates other than DAGs.

Both DGAT enzymes are involved in the intracellular TAG synthesis. Overexpression of either DGAT1 or DGAT2 in mammalian cells leads to increased DGAT 
activity of corresponding cell lysates [161]. Interestingly, specific enzymatic activity of DGAT1 is higher than that of DGAT2. On the contrary, cells expressing DGAT2 accumulate more TAG, contain bigger LDs, and incorporate more glycerol into the TAG moiety as compared to that of DGAT1 expressing cells [161], questioning the significance of in vitro activity data for the prediction of physiological relevance.

DGAT1 and DGAT2 differ in their acyl donor and acyl acceptor preference. Studies on murine DGAT1 have revealed preference for monounsaturated acyl donors, like C18:1-CoA, over saturated FA-CoAs, like C16:0-CoA [124, 157]; yet, another study on human DGAT1 selectivity found equal preferences for both, C16:0-CoA and C18:1CoA [162], questioning acyl donor preference of DGAT1. Intestinal human DGAT1 prefers $s n-2$ MAGs over $s n-3$ MAGs as substrates for the synthesis of $s n-1,2$ DAGs [162]. For DGAT2 no preferences for degree of saturation of FA-CoAs but a preference for medium-chained FACoAs (C12:0) as acyl donor and short- and mediumchained DAG species (e.g., C6:0, C8:0, C12:0) as acyl acceptor has been reported $[124,156]$. Furthermore, DGAT enzymes differ in regard to the isomerism of DAGs as acyl acceptor molecules. DGAT1 utilizes $s n-1,2 / 2,3$ DAGs more efficiently than $r a c-1,3$ DAGs. In contrast, DGAT2 exhibits the opposite acyl acceptor preference and prefers rac-1,3 DAGs [23].

An additional difference between DGAT enzymes is the sensitivity against magnesium which was demonstrated by in vitro experiments. High concentrations $(>50 \mathrm{mM})$ are described to entirely suppress DGAT2 activity whereas DGAT1 activity is much less affected [124].

The differences in subcellular localization as well as enzymatic properties of DGATs suggest different intracellular functions. The observation that only DGAT2 localizes to LDs together with the preference for $r a c-1,3$ DAGs suggests a coordinated action of DGAT2 and ATGL on LDs to facilitate a TAG hydrolysis/re-esterification cycle (futile cycle), potentially remodeling $s n-2$ FA ester species thereby replacing long-chain unsaturated with medium-chain fatty acids. Furthermore, the different intracellular localization of DGAT1/2 suggests that different DAG pools exist for DGATs. The one at LDs is only accessible for DGAT2. The other, at ER membranes, which is mostly supplied by DAG species ( $s n-1,2$ DAGs) derived from the de novo glycero(phospho)lipid synthesis, is accessible for both DGAT1 and DGAT2. This spatial and stereochemical separation of different DAG pools as well as of executing enzymes could be one explanation for the different phenotype of mice carrying global deletions of DGAT1 or DGAT2. The phenotypes of DGAT-deficient mice clearly demonstrate that these enzymes cannot functionally compensate for each other [161, 163]. DGAT1 knockout mice exhibit a moderate phenotype characterized by reduced TAG levels in several tissues (e.g., adipose tissues, skeletal muscle, liver) and resistance to diet-induced obesity [163]. In contrast, DGAT2 knockout mice die within the first day of life most likely as consequence of a severe skin defect and severe lipopenia [161]. The exact reason for these drastic differences of DGAT knockout mice is unknown. Recently, distinct functions of DGAT1 and DGAT2 in hepatic TAG synthesis have been reported. DGAT2 is described to mediate esterification of newly synthesized FAs, whereas DGAT1 catalyzes the synthesis of TAGs via utilization of exogenously supplied FAs [164, 165]. Whether this finding holds true for other tissues needs to be tested.

\section{Diacylglycerol lipases hydrolyze $s n-1,2$ DAGs at the plasma membrane}

HSL is well known to be rate limiting for DAG hydrolysis $[48,51]$. Yet, there are additional intracellular lipases which possess specific hydrolytic activities for DAGs, generating MAGs and FAs. In humans, two sn-1-specific DAG lipases have been identified, named DAG lipase $\alpha$ and $\beta$ (DAGL $\alpha$ and $\beta$ ) [166]. Both enzymes share $\sim 30 \%$ homology and comprise four predicted transmembranespanning domains as well as a serine lipase motif [166].

DAGL $\alpha$ is highly expressed in brain and pancreas and to a lower extent in macrophages and adipose tissues, while DAGL $\beta$ expression is highest in bone marrow, lymph nodes, spleen, and liver [166, 167]. Enzymatic characterization revealed that both enzymes hydrolyze the $s n-1,2$ DAG isomer ( $s n-2,3 / r a c-1,3$ were not tested), exhibiting three- to eightfold higher activity for the $s n-1$ over the $s n-2$ position of DAGs [166]. Furthermore, DAGL $\beta$ prefers DAG species, containing linoleic acid (C18:2) > $\mathrm{C} 18: 1>\mathrm{C} 20: 4>$ stearic acid (C18:0) at $s n-2$ position, whereas DAGL $\alpha$ shows equal activity against these DAG species [166].

Intracellularly, DAGL $\alpha$ localizes to the plasma membrane and hydrolyzes $s n-1,2$ DAGs generated by PLCdependent hydrolysis of phosphatidylinositides [168]. In contrast, DAGL $\beta$ also localizes to the LDs [168]. DAGLmediated breakdown of $s n-1,2$ DAGs at the plasma membrane results in the formation of $s n-2$ MAGs. Since PLs, the precursors of PLC-derived DAGs, exhibit a high abundance of C20:4 esterified at the $s n-2$ position of the glycerol backbone, the released MAG species is frequently 2-AG $[169,170]$. As already mentioned above, $2-\mathrm{AG}$ is the most abundant endocannabinoid in tissues and acts as ligand for cannabinoid receptors $\mathrm{CB} 1$ and $\mathrm{CB} 2$ [171]. In fact, the role of DAGL $\alpha$ and DAGL $\beta$ in the biosynthesis of 2-AG is evident from the phenotype of DAGL $\alpha$ or DAGL $\beta$-deficient mice [167]. In line with the tissue expression patterns, DAGL $\alpha$ 
knockout mice displayed $80 \%$ reduction in 2-AG levels in the brain, whereas DAGL $\beta$ knockout mice showed $90 \%$ reductions in 2-AG levels in the liver [167].

The role of DAGL enzymes in the hydrolysis of plasma membrane-derived $s n-1,2$ DAG species is well established. To date, it is questionable whether $s n$-1-specific DAGL enzymes are also involved in the degradation of DAG species of other sources such as rac-1,3 DAGs which originate from lipolysis-driven TAG breakdown at the LDs or $s n-1,2$ DAGs which also derive from de novo synthesis at the ER membrane.

\section{Diacylglycerol kinases are ubiquitously expressed and phosphorylate $s n-1,2$ DAG}

Diacylglycerol kinases (DGKs) catalyze the formation of PA by phosphorylation of the free hydroxyl $(-\mathrm{OH})$ group of DAG. Together with PAPases/lipins, DGKs are crucially involved in the maintenance of intracellular DAG and PA levels. So far, ten DGK isozymes have been identified in mammals [172, 173]. All mammalian DGK isozymes share two common structural features, a cysteine-rich $\mathrm{C} 1$ domain which is responsible for DAG binding and potentially involved in protein-protein interaction and a catalytic domain, responsible for enzymatic activity [174]. Virtually every tissue expresses at least one member of the DGK family. However, numerous tissues express several different DGK isozymes, e.g., all ten DGK isozymes can be found in brain extracts [175]. DGKs localize to multiple cellular compartments, including the nucleus, the plasma membrane, the cytoskeleton, the Golgi network, and the ER [176, 177]. Little is known about the specific functions of different DGK enzymes with regard to their organelle distribution. Whereas some isoforms translocate to the plasma membrane upon activating stimuli (most likely to funnel PLCderived DAGs to PA), others locate inside the nucleus, presumably regulating nuclear DAG levels [174].

DGKs are selective for $s n-1,2$ DAGs. Most likely, this is due to their $\mathrm{C} 1$ domain which shares high homology to the $s n-1,2$ DAG-specific binding motifs $\mathrm{C} 1 \mathrm{~A}$ and C1B of PKC [178-180]. However, to date it is unclear whether DGK isoforms are also capable to phosphorylate rac-1,3 or $s n-2,3$ DAG isoforms. Further enzymatic properties are known for DGKe. DGKe is the shortest DGK isoform which exhibits the lowest molecular weight and localizes either to the plasma membrane or to the ER. DGKe exhibits specificity for $s n-1,2$ DAG species [181] containing C18:0 at the $s n-1$ position and $\mathrm{C} 20: 4$ at the $s n-2$ position [182, 183] which is the major product of PLCmediated phosphoinositide hydrolysis [169]. DGKe is thought to terminate 20:4-DAG signaling and to counterbalance PIP2 hydrolysis by specifically phosphorylating
C20:4-containing DAGs to PA. In turn, generated PA would then be available for re-synthesis of PI and replenishment of PIP2 by consecutive phosphorylations to phosphatidylinositol 4-phosphate (PIP) and PIP2. This hypothesis is supported by the phenotype of mice carrying a global gene deletion DGKe which show downregulation of the 20:4-DAG to 20:4-PI lipid cycle [184].

\section{Diacylglycerol choline/ethanolamine phosphotransferases specifically utilize $s n-1,2$ DAGs at intracellular membranes}

All tissues and cell types can synthesize PC via the CDPcholine or better known as "Kennedy" pathway $[114,115]$. In an analog manner, PE can be formed via the CDPethanolamine pathway. The final step of both pathways, namely the direct conversion of DAGs to either PC or PE is catalyzed by CPT or CDP-ethanolamine:1,2-diacylglycerol ethanolaminephosphotransferase (EPT), respectively.

In humans, two proteins exhibit CPT activity. CPT1 acts as CDP-choline-specific enzyme while CEPT1 transfers both CDP-choline as well as CDP-ethanolamine [185, $186]$. Both proteins are integral membrane proteins and localize to the Golgi network and the ER membrane, respectively [187]. Human CPT1 mRNA expression is highest in testis, colon, small intestine, cardiac muscle, and spleen, whereas CEPT1 is expressed to a similar degree in all tissues examined [185, 186]. Due to the high CPT activity in cells, none of the two enzymes is thought to be rate-limiting in PC synthesis [188]. Since no purified mammalian CPT enzyme is available, information on substrate specificity is only available from structure/function analyses of CPT1 of $S$. cerevisiae. The yeast orthologue prefers $s n-1,2$ DAGs $(s n-2,3 / r a c-1,3$ were not tested), with a FA preference in the order of dipalmitolein $(\operatorname{diC} 16: 1)>\operatorname{diC} 16: 0=\mathrm{C} 18: 1 / \mathrm{C} 16: 0>\mathrm{C} 16: 0 / \mathrm{C} 18: 1$

DAG as substrates [189]. Selectivity studies using microsomal fractions of $S$. cerevisiae constitutively expressing human CEPT1 suggest a diC16:1 > C16:0/docosahexaenoic acid $(\mathrm{C} 22: 6)>\mathrm{C} 16: 0 / \mathrm{C} 18: 1>\operatorname{diC} 18: 1 \quad \mathrm{DAG}$ species preference for CEPT1 [187]. The third enzyme, ethanolamine phosphotransferase 1 (EPT1) selectively catalyzes the transfer of CDP-ethanolamine on $s n-1,2$ DAGs (sn-2,3/rac-1,3 were not tested), forming PE [190], and contributes only to $5 \%$ to cellular PC synthesis [191, 192]. Furthermore, EPT1 of $S$. cerevisiae prefers $s n-1,2$ DAGs (sn-2,3/rac-1,3 were not tested) species, with diC18:1 > diC16:1 > C16:0/C18:1 as FA chains in vitro [189]. Apart from the enzymatic activity, little is known about EPT1 expression pattern or biochemical properties. Interestingly, incubation of rat hepatocytes with radiolabeled ethanolamine results in a high specific accumulation of radioactivity in $\mathrm{C} 16: 0 / \mathrm{C} 22: 6-\mathrm{PE}$, suggesting that in 
mammals EPT activity may exhibit preference for C16:0/ C22:6-DAGs as substrates [193].

Taken together, CPT1, CEPT1, and EPT1 are involved in the synthesis of PLs, thereby consuming $s n-1,2$ DAGs.

\section{How DAG kicks into insulin signaling}

Besides the capability of DAGs to negatively regulate transient receptor potential canonical (TRPC) cation channels [194, 195], dysregulations of DAG metabolism and concomitant DAG accumulation is supposed to adversely affect cellular signaling involved in the development of different disease states, like insulin resistance (IR). Intracellular accumulation of DAG is thought to be connected to altered insulin responsiveness since ectopic DAG accumulation positively correlates with disturbed insulin signaling. This adverse effect of DAGs is thought to derive from the action of the PKC family members which are known to play a crucial role in many signaling pathways which control, e.g., cellular differentiation, and cell growth. The PKC family comprises three different PKC subgroups, namely conventional ( $\alpha, \beta 1, \beta 2$ and $\gamma$; cPKC), novel $(\delta, \varepsilon, \eta$ and $\theta ; \mathrm{nPKC})$ and atypical ( $\zeta$ and $\lambda / 1$; aPKC) PKCs. cPKCs and nPKCs display lipid-sensitive isoforms and are usually activated by PLC-derived $s n-1,2$ DAGs, either $\mathrm{Ca}^{2+}$ dependent (cPKC) or independent (nPKC). The $\mathrm{C} 1$ domain of conventional and novel PKCs binds DAGs and the tumor promoter phorbol ester with high affinity [196-198]. Hence, the activity of cPKCs and nPKCs is highly influenced by intracellular levels of DAGs. Noteworthy, earlier studies showed that only the $s n-1,2$ DAG isoform has the ability to activate PKCs, the other isoforms, $r a c-1,3$ and $s n-2,3$ are inactive [178-180]. Binding of cellular DAGs to members of the PKC family leads to their activation and translocation to the plasma membrane and subsequent phosphorylation of interacting proteins (such as insulin receptor substrate, IRS). It is assumed that a rise in cellular DAG levels may activate PKCs in an uncontrolled fashion.

So far, cellular effects driven by DAG accumulation have been mainly attributed to cPKCs and nPKCs. However, other "non-PKC" proteins also contain a high-affinity DAG/phorbol ester-binding $\mathrm{C} 1$ domain. To date a variety of DAG receptor proteins are described which belong to the families of PKD kinases, chimaerin Rac GTPase-activating proteins, Ras guanyl nucleotide-releasing proteins (RasGRPs), Munc13 scaffolding proteins, and formermentioned DAG kinases [199-205]. Importantly, members of these families have been described to affect cellular processes like cell adhesion (chimaerins) [206], cell proliferation/transformation (RasGRPs) [207, 208], secretory vesicle priming (Munc13s) [209-212], and protein transport (PKDs) [213, 214]. Thus, biological effects driven by DAG binding to proteins of these families must be considered when cellular DAG signaling is investigated. Several reviews on the physiological role of non-PKC C1 domain-containing proteins have elaborated the current knowledge [199-205]. The emerging number of metabolic diseases as result of the first world life style brings DAGdependent PKC signaling and related attenuation of insulin action in the focus of a multitude of present-day studies. Therefore, we focus in the following section on the PKC signaling axis in more detail.

Insulin signaling in myocytes and adipocytes is initiated by the binding of insulin to its receptor at the plasma membrane. Intracellularly, this activates a tyrosine kinase which consecutively phosphorylates one of the intracellular IRS 1-4 family members on several tyrosine residues [215, 216]. Activated IRSs serve as docking station for proteins like phosphatidylinositide-3-kinase (PI3K) and induce downstream effects which finally result in the translocation of glucose-transporter type 4 (GLUT4) to the plasma membrane [217]. Only plasma membrane-associated GLUT4 facilitates glucose uptake (Fig. 5a). Defects within this signaling cascade result in a loss of insulin sensitivity and consequently to IR of affected cells/tissues.

Of all PKC subgroups mainly nPKCs, more precisely PKC $\varepsilon$ and PKC $\theta$, adversely affect insulin signaling [218, 219]. Up to now several mechanisms have been identified by which nPKCs impair insulin action. Recent studies showed that PKC $\theta$ can phosphorylate IRS1 at $\operatorname{Ser}^{1101}$ which blocks insulin-stimulated tyrosine phosphorylation [220] and activation of PI3K [218]. As a consequence, GLUT4 does not translocate to the plasma membrane and glucose is not taken up (Fig. 5b).

\section{Mouse models for deregulated DAG metabolism}

Deregulation of DAG metabolism and concomitant DAG accumulation is thought to adversely affect cellular signaling and to be causally related to the development of various disease states, including IR. The phenotype of a number of genetic mouse models supports the hypothesis that increased DAG levels in insulin responsive tissues are causative for impaired insulin signaling. For example, overexpression of mitochondrial GPAT in mice leads to elevated levels of lysophosphatidic acid (LPA), DAG, and TAG in the liver and these mice develop hepatic IR in absence of a lipogenic diet or obesity [221]. Similarly, in obese Zucker rats (rats with non-functional leptin receptor) IR is associated with increased amounts of hepatic and muscle ceramide and DAG levels [222]. Another genetic mouse model arguing for DAG as mediator of IR are mice fed a high-ketogenic diet. These mice develop severe 


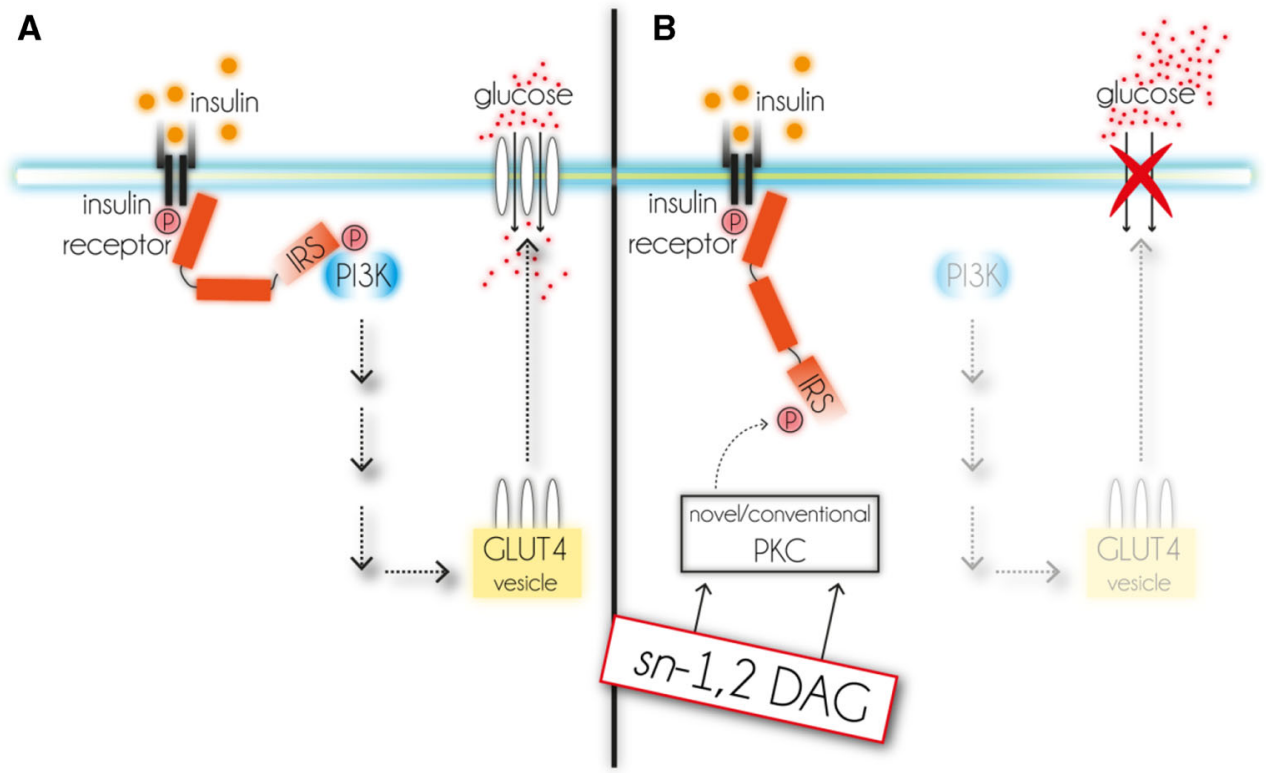

Fig. 5 Intracellular pathway of insulin signaling and proposed impairment by DAG. a Insulin binds to insulin receptor that activates IRS. This leads to the activation of PI3K and further downstream signaling which finally triggers the translocation of GLUT4 to the plasma membrane and enables glucose uptake. b $s n-1,2$ DAG

hepatic steatosis and severe hepatic IR which is associated with a $350 \%$ increase in hepatic DAG content [223]. These mice exhibit elevated levels of activated PKC $\varepsilon$ and decreased insulin-mediated tyrosine phosphorylation of IRS2. In mice overexpressing DGAT2 specifically in the liver, hepatic TAG as well as DAG and ceramide levels are markedly increased [224, 225]. These mice were first reported to have normal hepatic insulin sensitivity [224] but were recently identified to exhibit enhanced PKC $\varepsilon$ activation, accompanied by severe hepatic IR [225]. Furthermore, an interrelation between cellular DAG levels, PKCe activation, and hepatic IR has been observed in numerous models and has been extensively reviewed elsewhere [226]. Interestingly, a recent study discovered that hepatic DAG content of cytoplasmic LDs is the best predictor of IR in obese, non-diabetic individuals [227]. In the same study, they observed distinct localization of PKCE at cytoplasmic LDs as well as enhanced activation of PKC $\varepsilon$ [227]. So far, this study is unique in connecting DAG turnover at the LD with PKC signaling.

The phenotype of a number of other genetic mouse models argues against a causative role of non-plasma membrane-derived DAGs in the development of IR. For example, HSL knockout mice accumulate large amounts of DAG in adipose and non-adipose tissues [48, 51] but generally they do not develop IR. Unfortunately, the issue of whether or not HSL-deficient mice develop IR is conflicting since depending on the genetic background, some activates novel and conventional PKC isoforms which phosphorylate IRS. This event inhibits downstream effector signaling and GLUT4dependent glucose uptake. DAG diacylglycerol, GLUT4 glucose transporter $4, I R S$ insulin receptor substrate, $P$ phosphorylation, $P I 3 K$ phosphoinositide-3-kinase, $P K C$ protein kinase $\mathrm{C}$

HSL knockout strains show signs of impaired insulin signaling [228, 229] while others do not or show even increased insulin sensitivity [230, 231]. In contrast to mice, however, humans with mutated HSL develop severe diabetes which could be a result of ectopic lipid deposition in liver in combination with partial lipodystrophy [232]. Accumulation of rac-1,3 DAG, as determined in HSL-ko mice, is unlikely to be causative for the development of IR since $r a c-1,3$ DAG isomers are known not to activate PKCs [23, 178-180].

Another mouse model with cellular DAG accumulation was generated by antisense oligonucleotides (ASO)-mediated silencing of CGI-58 expression. ASO injection into mice mainly targets the liver, adipose tissues, and kidney and does not lead to a global silencing of expression. ASOCGI-58 mice on a high-fat diet regimen exhibit increased hepatic TAG, DAG, and ceramide levels. However, animals have been shown to exhibit improved insulin sensitivity and glucose tolerance [233]. The lack of adverse insulin signaling despite DAG accumulation in ASO-CGI58-treated mice was explained by the sequestration of DAG molecules in LDs so that they were unable to interact with PKCs [234].

A recent study reported that overexpression of ATGL in cultured myotubes leads to increased DAG and ceramides levels which was found to be associated with impaired insulin signaling [235]. This suggests that deregulation of TAG metabolism might be linked to insulin signaling. Yet, 
mice globally lacking ATGL or mice overexpressing ATGL specifically in adipose tissue display also deregulated TAG metabolism, but show improved glucose tolerance [22] or are protected from IR [236], respectively, questioning a causal link between LD-associated TAG deregulation and insulin signaling.

In summary, several of the above-mentioned studies suggest a causal link between DAG, PKC signaling, and the development of IR. In this context, DAG isomerism as well as intracellular DAG compartmentation might be of crucial importance. As outlined above, a number of metabolic reactions degrade or consume DAGs. Yet, they are located at different cellular compartments and DAG isoforms involved in these reactions are stereochemically different. Earlier studies clearly demonstrated that the DAG-binding $\mathrm{C} 1$ domain of PKCs is highly specific for $s n$-1,2 DAGs. Other isoforms, like $s n-2,3$ or $r a c-1,3$ DAGs, are unable to activate PKCs [178-180] and hence display no signaling properties. Due to the inability of DAG isoforms, other than $s n-1,2 \mathrm{DAG}$, to activate PKCs it appears crucial to precisely determine DAG isomerism under normo-physiological and patho-physiological conditions.

\section{3-Pool model of DAG metabolism, conclusions, and perspectives}

DAG metabolism involves a battery of enzymes at spatially different cellular locations with distinct enzymatic properties and selectivities. For the sake of simplicity many studies in the past have ignored spatial and stereochemical issues and have correlated total cellular DAG levels with PKC activation as proof for causality between cellular DAG levels and DAG signaling. Future studies on DAG-producing or -consuming enzymes need to address these issues of stereoselectivity of DAG species and their cellular localization. This will help to further elaborate intracellular DAG metabolism and functions of different DAG isomers which is required to comprehend the metabolic implications of normo-physiological and pathological DAG metabolism and function. To date it is appreciated that DAGs exist in different stereo/regioisoforms and it is assumed that certain DAG isoforms exhibit specified intracellular functions at different cellular locations and processes. Furthermore, the amount of DAGs at different sites (e.g., intracellular membranes vs plasma

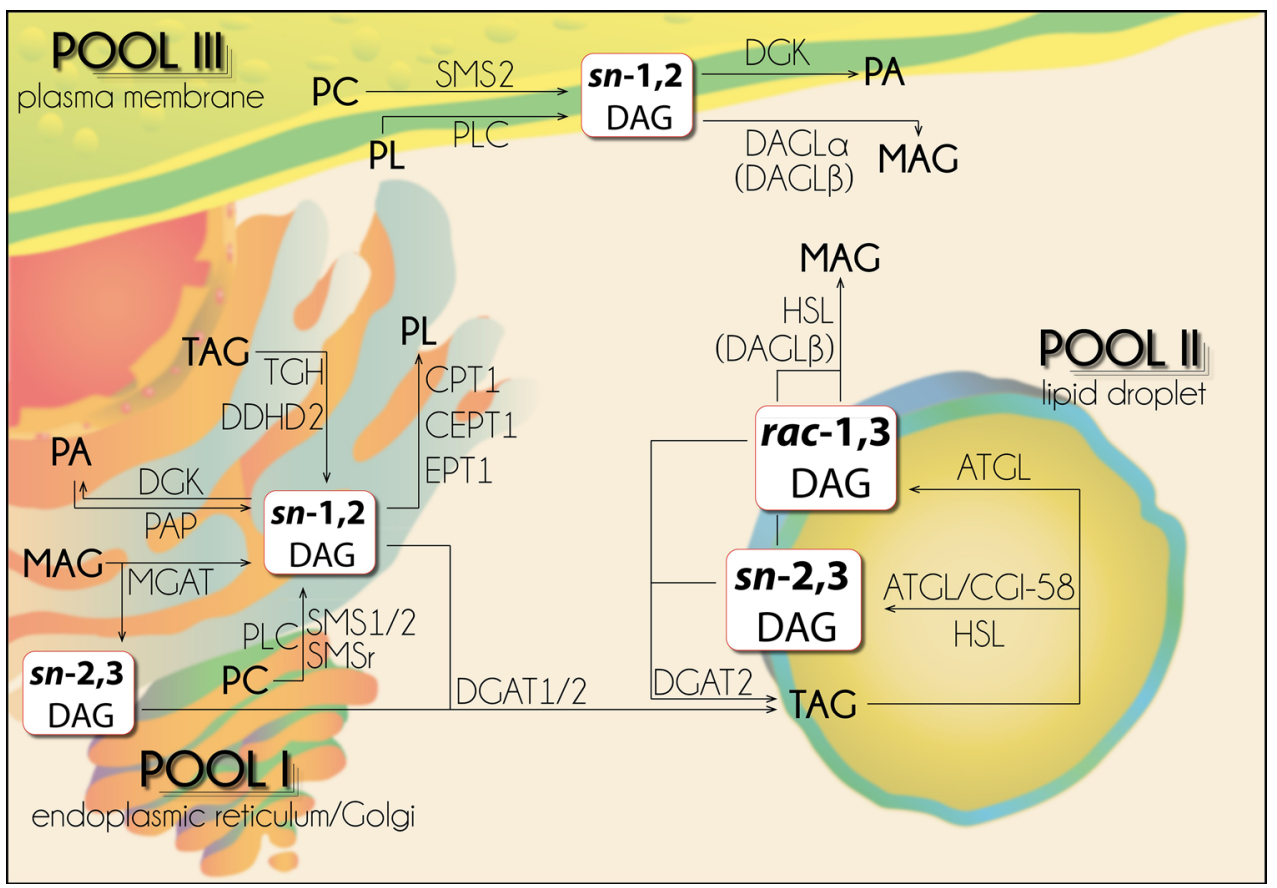

Fig. 6 "3-Pool" compartmentation model of intracellular diacylglycerols. Intracellular diacylglycerols differ in their stereo/regio conformation, compartmentation, and generating/consuming enzymes. For detailed description see text. $A T G L$ adipose triglyceride lipase, CGI-58 comparative gene identification-58, CEPT CDP-ethanolamine/choline:1,2-diacylglycerol ethanolaminephosphotransferase CPT, CDP-choline:1,2-diacylglycerol ethanolaminephosphotransferase, $D A G$ diacylglycerol, $D A G L$ DAG lipase, DGAT DAG-O- acyltransferase, DGK DAG kinase, EPT CDP-ethanolamine:1,2diacylglycerol ethanolaminephosphotransferase, $H S L$ hormonesensitive lipase, $M A G$ monoacylglycerol, MGAT monoacylglycerol- $O$-acyltransferase, $P A$ phosphatidic acid, $P A P$ PA phosphohydrolase/lipin, $P C$ phosphatidylcholine, $P L$ phospholipid, $P L C$ phospholipase C, $S M S(r)$ sphingomyelin synthase (related), $T A G$ triacylglycerol 
membranes) depends on various stimuli or metabolic processes and underlies a remarkable spatiotemporal dynamic [237-239].

The stereochemistry of DAG isomers as well as the distinct localizations and activities of DAG-generating/consuming enzymes suggest a spatial separation of DAG pools which can be outlined in a "3-pool model" of intracellular DAG compartmentation [23]. This model describes that 3 distinct intracellular DAG pools exist at the ER/Golgi network, the $\mathrm{LD}$, and the plasma membrane which differ to some extent in their DAG isomerism and are accessible for different sets of enzymes.

"Pool I" is located at the ER/Golgi network and consists of $s n-1,2$ DAGs. This DAG pool is generated by de novo glycero(phospho)lipid synthesis either by PAPases/lipins or MGAT enzymes, as by-product of SM synthesis catalyzed by SMSs, or as product of TAG hydrolysis by lipases like TGH/Ces3 or DDHD2. Furthermore, $s n-1,2$ DAGs of this pool can be utilized by DGKs forming PA, DGAT enzymes generating TAG, and PL-generating enzymes like CEPT1, CPT1, and EPT1 (Fig. 6).

Lipolysis-derived DAGs represent "Pool II" which is located at cytoplasmic LDs. This pool comprises rac-1,3 and $s n-2,3$ DAGs and is fueled by the TAG hydrolytic activities of ATGL and HSL. The rac-1,3 DAG isomer is generated by TAG hydrolysis of ATGL. The $s n-2,3$ DAG isomer is generated by TAG hydrolysis of HSL and of ATGL, in addition to the rac-1,3 DAG isomer, when coactivated by CGI-58. DAGs of this pool can be re-esterified to TAGs exclusively by DGAT2 or further be catabolized to $s n$-2 MAGs by HSL(or DAGL $\beta$ )-mediated hydrolysis (Fig. 6).

"Pool III" is located at the plasma membrane and consists of $s n-1,2$ DAGs. These $s n-1,2$ DAGs are generated either by PLC-dependent breakdown of PLs or during SM production catalyzed by SMS2. DAGs of "Pool III" can serve as precursors for the synthesis of PA through DGKcatalyzed phosphorylation or can be hydrolyzed to $s n-2$ MAGs by membrane-associated DAGL $\alpha$ (or DAGL $\beta$ ). So far, only $s n-1,2$ DAGs of "Pool III" are established to be involved in DAG signaling events, executed by nPKC and cPKC isoforms (Fig. 6).

The differences in stereo/regiochemistry of involved DAGs as well as the topological separation of these three DAG pools may provide explanations to previously puzzling data in regard to DAG-induced signaling, lipid metabolism, and metabolic disorders. Furthermore, the involvement of so far unidentified DAG-specific binding proteins and/or DAG isomerases could interconnect different intracellular sources of DAGs and could explain seemingly contradicting findings on DAG function and signaling potential. Following a multiplicity of studies focusing on the role of DAGs and in-depth reviews of DAG metabolism and functions [240-242], the future attention will further shift to the question which role is attributed to different DAG isomers as well as to different DAG species, in respect to their FA composition, in intracellular metabolism. Unraveling these issues will finally paint a more complete picture of the interrelation between lipid metabolism, intracellular signaling, and certain disease pathologies.

Acknowledgments We apologize to authors whose studies have not been cited due to space limitations. This work was supported by the grant P25193 (A.L.) which is funded by the Austrian Science Fund (FWF). We thank Mag. Dr. Ulrike Taschler for carefully reading the manuscript.

Open Access This article is distributed under the terms of the Creative Commons Attribution 4.0 International License (http://creativecommons.org/licenses/by/4.0/), which permits unrestricted use, distribution, and reproduction in any medium, provided you give appropriate credit to the original author(s) and the source, provide a link to the Creative Commons license, and indicate if changes were made.

\section{References}

1. Prelog V, Helmchen G (1982) Basic principles of the CIP system and proposals for a revision. Angew Chemie, Int Ed english 21:567-583

2. Cahn RS, Ingold C, Prelog V (1966) Specifications of molecular chirality. Angew Chemie Int Ed english 5:385-415

3. Tauchi-Sato K, Ozeki S, Houjou T et al (2002) The surface of lipid droplets is a phospholipid monolayer with a unique fatty acid composition. J Biol Chem 277:44507-44512

4. Murphy DJ, Vance J (1999) Mechanisms of lipid-body formation. Trends Biochem Sci 24:109-115

5. Gibbons GF, Wiggins D, Brown A-M, Hebbachi A-M (2004) Synthesis and function of hepatic very-low-density lipoprotein. Biochem Soc Trans 32:59-64

6. Zimmermann R, Strauss JG, Haemmerle G et al (2004) Fat mobilization in adipose tissue is promoted by adipose triglyceride lipase. Science 306:1383-1386

7. Villena JA, Roy S, Sarkadi-Nagy E et al (2004) Desnutrin, an adipocyte gene encoding a novel patatin domain-containing protein, is induced by fasting and glucocorticoids: ectopic expression of desnutrin increases triglyceride hydrolysis. J Biol Chem 279:47066-47075

8. Jenkins CM, Mancuso DJ, Yan W et al (2004) Identification, cloning, expression, and purification of three novel human calcium-independent phospholipase A2 family members possessing triacylglycerol lipase and acylglycerol transacylase activities. J Biol Chem 279:48968-48975

9. Wilson PA, Gardner SD, Lambie NM et al (2006) Characterization of the human patatin-like phospholipase family. J Lipid Res 47:1940-1949

10. Rydel TJ, Williams JM, Krieger E et al (2003) The crystal structure, mutagenesis, and activity studies reveal that patatin is a lipid acyl hydrolase with a Ser-Asp catalytic dyad. Biochemistry 42:6696-6708

11. Senda K, Yoshioka H, Doke N, Kawakita K (1996) A cytosolic phospholipase A2 from potato tissues appears to be patatin. Plant Cell Physiol 37:347-353 
12. Granneman JG, Moore HP, Granneman RL et al (2006) Analysis of lipolytic protein trafficking and interactions in adipocytes. J Biol Chem 282:5726-5735

13. Taschler U, Schreiber R, Chitraju C et al (2015) Adipose triglyceride lipase is involved in the mobilization of triglyceride and retinoid stores of hepatic stellate cells. Biochim Biophys Acta Mol Cell Biol Lipids 1851:937-945

14. Gao JG, Simon M (2007) A comparative study of human GS2, its paralogues, and its rat orthologue. Biochem Biophys Res Commun 360:501-506

15. Lake AC, Sun Y, Li JL et al (2005) Expression, regulation, and triglyceride hydrolase activity of Adiponutrin family members. J Lipid Res 46:2477-2487

16. Kershaw EE, Schupp M, Guan HP et al (2007) PPARgamma regulates adipose triglyceride lipase in adipocytes in vitro and in vivo. Am J Physiol Endocrinol Metab 293:E1736-E1745

17. Kralisch S, Klein J, Lossner U et al (2005) Isoproterenol, TNFalpha, and insulin downregulate adipose triglyceride lipase in 3T3-L1 adipocytes. Mol Cell Endocrinol 240:43-49

18. Jocken JWE, Langin D, Smit E et al (2007) Adipose triglyceride lipase and hormone-sensitive lipase protein expression is decreased in the obese insulin-resistant state. J Clin Endocrinol Metab 92:2292-2299

19. Lass A, Zimmermann R, Haemmerle G et al (2006) Adipose triglyceride lipase-mediated lipolysis of cellular fat stores is activated by CGI-58 and defective in Chanarin-Dorfman Syndrome. Cell Metab 3:309-319

20. Yang X, Lu X, Lombes $M$ et al (2010) The G(0)/G(1) switch gene 2 regulates adipose lipolysis through association with adipose triglyceride lipase. Cell Metab 11:194-205

21. Schweiger M, Paar M, Eder C et al (2012) G0/G1 switch gene-2 regulates human adipocyte lipolysis by affecting activity and localization of adipose triglyceride lipase. J Lipid Res 53:2307-2317

22. Haemmerle G, Lass A, Zimmermann R et al (2006) Defective lipolysis and altered energy metabolism in mice lacking adipose triglyceride lipase. Science 312:734-737

23. Eichmann TO, Kumari M, Haas J et al (2012) Studies on the substrate and stereo/regioselectivity of adipose triglyceride lipase, hormone-sensitive lipase, and diacylglycerol- $O$-acyltransferase enzymes. J Biol Chem 287(49):41446-41457

24. Hollenberg CH, Raben MS, Astwood EB (1961) The lipolytic response to corticotropin. Endocrinology 68:589-598

25. Vaughan M, Berger JE, Steinberg D (1964) Hormone-sensitive lipase and monoglyceride lipase activities in adipose tissue. J Biol Chem 239:401-409

26. Holm C (2003) Molecular mechanisms regulating hormonesensitive lipase and lipolysis. Biochem Soc Trans 31:1120-1124

27. Sztalryd C, Kraemer FB (1994) Regulation of hormone-sensitive lipase during fasting. Am J Physiol 266:E179-E185

28. Osterlund T, Danielsson B, Degerman E et al (1996) Domainstructure analysis of recombinant rat hormone-sensitive lipase. Biochem J 319(Pt 2):411-420

29. Osterlund T, Beussman DJ, Julenius K et al (1999) Domain identification of hormone-sensitive lipase by circular dichroism and fluorescence spectroscopy, limited proteolysis, and mass spectrometry. J Biol Chem 274:15382-15388

30. Osterlund T, Contreras JA, Holm C (1997) Identification of essential aspartic acid and histidine residues of hormone-sensitive lipase: apparent residues of the catalytic triad. FEBS Lett 403:259-262

31. Langin D, Laurell H, Holst LS et al (1993) Gene organization and primary structure of human hormone-sensitive lipase: possible significance of a sequence homology with a lipase of Moraxella TA144, an antarctic bacterium. Proc Natl Acad Sci USA 90:4897-4901
32. Shen WJ, Patel S, Hong R, Kraemer FB (2000) Hormone-sensitive lipase functions as an oligomer. Biochemistry 39:2392-2398

33. Stralfors P, Belfrage P (1983) Phosphorylation of hormonesensitive lipase by cyclic AMP-dependent protein kinase. J Biol Chem 258:15146-15152

34. Shen WJ, Patel S, Natu V, Kraemer FB (1998) Mutational analysis of structural features of rat hormone-sensitive lipase. Biochemistry 37:8973-8979

35. Anthonsen MW, Ronnstrand L, Wernstedt C et al (1998) Identification of novel phosphorylation sites in hormone-sensitive lipase that are phosphorylated in response to isoproterenol and govern activation properties in vitro. J Biol Chem 273:215-221

36. Belfrage P, Fredrikson G, Olsson H, Stralfors P (1984) Regulation of adipose tissue lipolysis through reversible phosphorylation of hormone-sensitive lipase. Adv Cyclic Nucleotide Protein Phosphorylation Res 17:351-359

37. Belfrage P, Fredrikson G, Nilsson NO, Stralfors P (1981) Regulation of adipose-tissue lipolysis by phosphorylation of hormone-sensitive lipase. Int J Obes 5:635-641

38. Stralfors P, Bjorgell P, Belfrage P (1984) Hormonal regulation of hormone-sensitive lipase in intact adipocytes: identification of phosphorylated sites and effects on the phosphorylation by lipolytic hormones and insulin. Proc Natl Acad Sci USA 81:3317-3321

39. Garton AJ, Yeaman SJ (1990) Identification and role of the basal phosphorylation site on hormone-sensitive lipase. Eur J Biochem 191:245-250

40. Blanchette-Mackie EJ, Dwyer NK, Barber T et al (1995) Perilipin is located on the surface layer of intracellular lipid droplets in adipocytes. J Lipid Res 36:1211-1226

41. Brasaemle DL, Rubin B, Harten IA et al (2000) Perilipin A increases triacylglycerol storage by decreasing the rate of triacylglycerol hydrolysis. J Biol Chem 275:38486-38493

42. Miyoshi H, Perfield JW 2nd, Souza SC et al (2007) Control of adipose triglyceride lipase action by serine 517 of perilipin A globally regulates protein kinase A-stimulated lipolysis in adipocytes. J Biol Chem 282:996-1002

43. Miyoshi H, Souza SC, Zhang HH et al (2006) Perilipin promotes HSL-mediated adipocyte lipolysis via phosphorylation-dependent and independent mechanisms. J Biol Chem 281(23): 15837-15844

44. Tansey JT, Huml AM, Vogt R et al (2003) Functional studies on native and mutated forms of perilipins. A role in protein kinase A-mediated lipolysis of triacylglycerols. J Biol Chem 278:8401-8406

45. Sztalryd C, Xu G, Dorward H et al (2003) Perilipin A is essential for the translocation of hormone-sensitive lipase during lipolytic activation. J Cell Biol 161:1093-1103

46. Egan JJ, Greenberg AS, Chang MK et al (1992) Mechanism of hormone-stimulated lipolysis in adipocytes: translocation of hormone-sensitive lipase to the lipid storage droplet. Proc Natl Acad Sci USA 89:8537-8541

47. Su CL, Sztalryd C, Contreras JA et al (2003) Mutational analysis of the hormone-sensitive lipase translocation reaction in adipocytes. J Biol Chem 278:43615-43619

48. Osuga J, Ishibashi S, Oka T et al (2000) Targeted disruption of hormone-sensitive lipase results in male sterility and adipocyte hypertrophy, but not in obesity. Proc Natl Acad Sci USA 97:787-792

49. Harada K, Shen WJ, Patel S et al (2003) Resistance to high-fat diet-induced obesity and altered expression of adipose-specific genes in HSL-deficient mice. Am J Physiol Endocrinol Metab 285:E1182-E1195

50. Zimmermann R, Haemmerle G, Wagner EM et al (2003) Decreased fatty acid esterification compensates for the reduced 
lipolytic activity in hormone-sensitive lipase-deficient white adipose tissue. J Lipid Res 44:2089-2099

51. Haemmerle G, Zimmermann R, Hayn M et al (2002) Hormonesensitive lipase deficiency in mice causes diglyceride accumulation in adipose tissue, muscle, and testis. J Biol Chem 277:4806-4815

52. Wang SP, Laurin N, Himms-Hagen J et al (2001) The adipose tissue phenotype of hormone-sensitive lipase deficiency in mice. Obes Res 9:119-128

53. Fredrikson G, Stralfors P, Nilsson NO, Belfrage P (1981) Hormone-sensitive lipase of rat adipose tissue. Purification and some properties. J Biol Chem 256:6311-6320

54. Wei S, Lai K, Patel S et al (1997) Retinyl ester hydrolysis and retinol efflux from BFC-1beta adipocytes. J Biol Chem 272:14159-14165

55. Tsujita T, Ninomiya H, Okuda H (1989) P-nitrophenyl butyrate hydrolyzing activity of hormone-Sensitive lipase from bovine adipose tissue. J Lipid Res 30:997-1004

56. Fredrikson G, Belfrage P (1983) Positional specificity of hormone-sensitive lipase from rat adipose tissue. J Biol Chem 258:14253-14256

57. Rodriguez JA, Ben Ali Y, Abdelkafi S et al (2010) In vitro stereoselective hydrolysis of diacylglycerols by hormone-sensitive lipase. Biochim Biophys Acta 1801:77-83

58. Gavino VC, Gavino GR (1992) Adipose hormone-sensitive lipase preferentially releases polyunsaturated fatty acids from triglycerides. Lipids 27:950-954

59. Schweiger M, Schreiber R, Haemmerle G et al (2006) Adipose triglyceride lipase and hormone-sensitive lipase are the major enzymes in adipose tissue triacylglycerol catabolism. J Biol Chem 281:40236-40241

60. Lehner R, Verger R (1997) Purification and characterization of a porcine liver microsomal triacylglycerol hydrolase. Biochemistry $36: 1861-1868$

61. Matsushima M, Inoue H, Ichinose M et al (1991) The nucleotide and deduced amino acid sequences of porcine liver prolinebeta-naphthylamidase. Evidence for the identity with carboxylesterase. FEBS Lett 293:37-41

62. Au-Young J, Fielding CJ (1992) Synthesis and secretion of wild-type and mutant human plasma cholesteryl ester transfer protein in baculovirus-transfected insect cells: the carboxyl-terminal region is required for both lipoprotein binding and catalysis of transfer. Proc Natl Acad Sci USA 89:4094-4098

63. Drayna D, Jarnagin AS, McLean J et al (1987) Cloning and sequencing of human cholesteryl ester transfer protein cDNA. Nature 327:632-634

64. Robbi M, Beaufay H (1991) The $\mathrm{COOH}$ terminus of several liver carboxylesterases targets these enzymes to the lumen of the endoplasmic reticulum. J Biol Chem 266:20498-20503

65. Satoh T, Hosokawa M (1998) The mammalian carboxylesterases: from molecules to functions. Annu Rev Pharmacol Toxicol 38:257-288

66. Dolinsky VW, Sipione S, Lehner R, Vance DE (2001) The cloning and expression of a murine triacylglycerol hydrolase cDNA and the structure of its corresponding gene. Biochim Biophys Acta 1532:162-172

67. Alam M, Vance DE, Lehner R (2002) Structure-function analysis of human triacylglycerol hydrolase by site-directed mutagenesis: identification of the catalytic triad and a glycosylation site. Biochemistry 41:6679-6687

68. Dolinsky VW, Gilham D, Alam M et al (2004) Triacylglycerol hydrolase: role in intracellular lipid metabolism. Cell Mol Life Sci 61:1633-1651

69. Dolinsky VW, Douglas DN, Lehner R, Vance DE (2004) Regulation of the enzymes of hepatic microsomal triacylglycerol lipolysis and re-esterification by the glucocorticoid dexamethasone. Biochem J 378:967-974

70. Wang H, Wei E, Quiroga AD et al (2010) Altered lipid droplet dynamics in hepatocytes lacking triacylglycerol hydrolase expression. Mol Biol Cell 21:1991-2000

71. Wei E, Ben Ali Y, Lyon J et al (2010) Loss of TGH/Ces3 in mice decreases blood lipids, improves glucose tolerance, and increases energy expenditure. Cell Metab 11:183-193

72. Nakajima KI, Sonoda H, Mizoguchi T et al (2002) A novel phospholipase A1 with sequence homology to a mammalian Sec23p-interacting protein, p125. J Biol Chem 277:11329-11335

73. Inloes JM, Hsu K-L, Dix MM et al (2014) The hereditary spastic paraplegia-related enzyme DDHD2 is a principal brain triglyceride lipase. Proc Natl Acad Sci 111:14924-14929

74. Okazaki H, Igarashi M, Nishi M et al (2006) Identification of a novel member of the carboxylesterase family that hydrolyzes triacylglycerol: a potential role in adipocyte lipolysis. Diabetes 55:2091-2097

75. Lee WC, Salido E, Yen PH (1994) Isolation of a new gene GS2 (DXS1283E) from a CpG island between STS and KAL1 on Xp22.3. Genomics 22:372-376

76. Gao J, Simon M (2005) Identification of a novel keratinocyte retinyl ester hydrolase as a transacylase and lipase. J Invest Dermatol 124:1259-1266

77. Baulande S, Lasnier F, Lucas M, Pairault J (2001) Adiponutrin, a transmembrane protein corresponding to a novel dietary- and obesity-linked mRNA specifically expressed in the adipose lineage. J Biol Chem 276:33336-33344

78. Huang Y, He S, Li JZ et al (2010) A feed-forward loop amplifies nutritional regulation of PNPLA3. Proc Natl Acad Sci USA 107:7892-7897

79. He S, McPhaul C, Li JZ et al (2010) A sequence variation (I148M) in PNPLA3 associated with nonalcoholic fatty liver disease disrupts triglyceride hydrolysis. J Biol Chem 285:6706-6715

80. Kershaw EE, Hamm JK, Verhagen LA et al (2006) Adipose triglyceride lipase: function, regulation by insulin, and comparison with adiponutrin. Diabetes 55:148-157

81. Pirazzi C, Valenti L, Motta BM et al (2014) PNPLA3 has retinyl-palmitate lipase activity in human hepatic stellate cells. Hum Mol Genet 23:4077-4085

82. Huang Y, Cohen JC, Hobbs HH (2011) Expression and characterization of a PNPLA3 protein isoform (I148M) associated with nonalcoholic fatty liver disease. J Biol Chem 286:37085-37093

83. Basantani MK, Sitnick MT, Cai L et al (2011) Pnpla3/ Adiponutrin deficiency in mice does not contribute to fatty liver disease or metabolic syndrome. J Lipid Res 52:318-329

84. Li JZ, Huang Y, Karaman R et al (2012) Chronic overexpression of PNPLA3I148M in mouse liver causes hepatic steatosis. J Clin Invest 122:4130-4144

85. Qiao A, Liang J, Ke Y et al (2011) Mouse patatin-like phospholipase domain-containing 3 influences systemic lipid and glucose homeostasis. Hepatology 54:509-521

86. Smagris E, BasuRay S, Li J et al (2014) Pnpla3I148M knockin mice accumulate PNPLA3 on lipid droplets and develop hepatic steatosis. Hepatology 61:108-118

87. Kumari M, Schoiswohl G, Chitraju C et al (2012) Adiponutrin functions as a nutritionally regulated lysophosphatidic acid acyltransferase. Cell Metab 15:691-702

88. Li H, Zhang L, Yin D et al (2010) Targeting phosphatidylcholine-specific phospholipase $\mathrm{C}$ for atherogenesis therapy. Trends Cardiovasc Med 20:172-176

89. Ramoni C, Spadaro F, Barletta B et al (2004) Phosphatidylcholine-specific phospholipase $\mathrm{C}$ in mitogen-stimulated fibroblasts. Exp Cell Res 299:370-382 
90. Rhee SG (2001) Regulation of phosphoinositide-specific phospholipase C. Annu Rev Biochem 70:281-312

91. Cockcroft S (2006) The latest phospholipase C, PLCeta, is implicated in neuronal function. Trends Biochem Sci 31:4-7

92. Bunney TD, Katan M (2006) Phospholipase C epsilon: linking second messengers and small GTPases. Trends Cell Biol 16:640-648

93. Suh PG, Park JI, Manzoli L et al (2008) Multiple roles of phosphoinositide-specific phospholipase C isozymes. BMB Rep 41:415-434

94. Fukami K, Inanobe S, Kanemaru K, Nakamura Y (2010) Phospholipase $\mathrm{C}$ is a key enzyme regulating intracellular calcium and modulating the phosphoinositide balance. Prog Lipid Res 49:429-437

95. Ullman MD, Radin NS (1974) The enzymatic formation of sphingomyelin from ceramide and lecithin in mouse liver. J Biol Chem 249:1506-1512

96. Voelker DR, Kennedy EP (1982) Cellular and enzymic synthesis of sphingomyelin. Biochemistry 21:2753-2759

97. Huitema K, van den Dikkenberg J, Brouwers JFHM, Holthuis JCM (2004) Identification of a family of animal sphingomyelin synthases. EMBO J 23:33-44

98. Tafesse FG, Ternes P, Holthuis JCM (2006) The multigenic sphingomyelin synthase family. J Biol Chem 281:29421-29425

99. Lee NPY, Mruk DD, Xia W, Cheng CY (2007) Cellular localization of sphingomyelin synthase 2 in the seminiferous epithelium of adult rat testes. J Endocrinol 192:17-32

100. Baron CL, Malhotra V (2002) Role of diacylglycerol in PKD recruitment to the TGN and protein transport to the plasma membrane. Science 295:325-328

101. Yeaman C, Ayala MI, Wright JR et al (2004) Protein kinase D regulates basolateral membrane protein exit from trans-Golgi network. Nat Cell Biol 6:106-112

102. Tafesse FG, Huitema K, Hermansson M et al (2007) Both sphingomyelin synthases SMS1 and SMS2 are required for sphingomyelin homeostasis and growth in human HeLa cells. J Biol Chem 282:17537-17547

103. Vacaru AM, Tafesse FG, Ternes P et al (2009) Sphingomyelin synthase-related protein $\mathrm{SMSr}$ controls ceramide homeostasis in the ER. J Cell Biol 185:1013-1027

104. Ternes P, Brouwers JFHM, van den Dikkenberg J, Holthuis JCM (2009) Sphingomyelin synthase SMS2 displays dual activity as ceramide phosphoethanolamine synthase. J Lipid Res 50:2270-2277

105. Bell RM, Coleman RA (1980) Enzymes of glycerolipid synthesis in eukaryotes. Annu Rev Biochem 49:459-487

106. Coleman RA, Lee DP (2004) Enzymes of triacylglycerol synthesis and their regulation. Prog Lipid Res 43:134-176

107. Coleman RA, Mashek DG (2011) Mammalian triacylglycerol metabolism: synthesis, lipolysis, and signaling. Chem Rev 111:6359-6386

108. Kornberg A, Pricer WE (1953) Enzymatic esterification of alpha-glycerophosphate by long chain fatty acids. J Biol Chem 204:345

109. Burblitz C, Kennedy EP (1954) Synthesis of phosphatidates in isolated mitochondria. J Biol Chem 211:951

110. Johnston M, Schultz D, Schiller M (1970) The utilization of the alpha-glycerophosphate and monoglyceride pathways for phosphatidyl choline biosynthesis in the intestine. Biochim Biophys Acta 218:124-133

111. Phan CT, Tso P (2001) Intestinal lipid absorption and transport. Front Biosci 6:D299-D319

112. Polheim D, David JS, Schultz FM et al (1973) Regulation of triglyceride biosynthesis in adipose and intestinal tissue. J Lipid Res 14:415-421
113. Kennedy EP, Smith SW, Weiss SB (1956) New synthesis of lecithin in an isolated enzyme system. Nature 178:594-595

114. Kennedy EP (1957) Biosynthesis of phospholipids. Fed Proc $16: 847-853$

115. Gibellini F, Smith TK (2010) The Kennedy pathway-De novo synthesis of phosphatidylethanolamine and phosphatidylcholine. IUBMB Life 62:414-428

116. Peterfy M, Phan J, Xu P, Reue K (2001) Lipodystrophy in the fld mouse results from mutation of a new gene encoding a nuclear protein, lipin. Nat Genet 27:121-124

117. Donkor J, Sariahmetoglu M, Dewald J et al (2007) Three mammalian lipins act as phosphatidate phosphatases with distinct tissue expression patterns. J Biol Chem 282:3450-3457

118. Harris TE, Huffman TA, Chi A et al (2007) Insulin controls subcellular localization and multisite phosphorylation of the phosphatidic acid phosphatase, lipin 1. J Biol Chem 282:277-286

119. Cascales C, Mangiapane EH, Brindley DN (1984) Oleic acid promotes the activation and translocation of phosphatidate phosphohydrolase from the cytosol to particulate fractions of isolated rat hepatocytes. Biochem J 219:911-916

120. Phan J, Reue K (2005) Lipin, a lipodystrophy and obesity gene. Cell Metab 1:73-83

121. Yen CL Jr, Farese RV (2003) MGAT2, a monoacylglycerol acyltransferase expressed in the small intestine. J Biol Chem 278:18532-18537

122. Yen CL, Stone SJ, Cases S et al (2002) Identification of a gene encoding MGAT1, a monoacylglycerol acyltransferase. Proc Natl Acad Sci USA 99:8512-8517

123. Cheng D, Nelson TC, Chen J et al (2003) Identification of acyl coenzyme A:monoacylglycerol acyltransferase 3 , an intestinal specific enzyme implicated in dietary fat absorption. J Biol Chem 278:13611-13614

124. Cases S, Stone SJ, Zhou P et al (2001) Cloning of DGAT2, a second mammalian diacylglycerol acyltransferase, and related family members. J Biol Chem 276:38870-38876

125. Cao J, Lockwood J, Burn P, Shi Y (2003) Cloning and functional characterization of a mouse intestinal acylCoA:monoacylglycerol acyltransferase, MGAT2. J Biol Chem 278:13860-13866

126. Cao J, Burn P, Shi Y (2003) Properties of the mouse intestinal acyl-CoA:monoacylglycerol acyltransferase, MGAT2. J Biol Chem 278:25657-25663

127. Cao J, Cheng L, Shi Y (2007) Catalytic properties of MGAT3, a putative triacylgycerol synthase. J Lipid Res 48:583-591

128. Brindley DN, Hubscher G (1966) The effect of chain length on the activation and subsequent incorporation of fatty acids into glycerides by the small intestinal mucosa. Biochim Biophys Acta 125:92-105

129. Carriere F, Rogalska E, Cudrey C et al (1997) In vivo and in vitro studies on the stereoselective hydrolysis of tri- and diglycerides by gastric and pancreatic lipases. Bioorg Med Chem 5:429-435

130. Jennens ML, Lowe ME (1995) Rat GP-3 is a pancreatic lipase with kinetic properties that differ from colipase-dependent pancreatic lipase. J Lipid Res 36:2374-2382

131. Thirstrup K, Verger R, Carrière F (1994) Evidence for a pancreatic lipase subfamily with new kinetic properties. Biochemistry 33:2748-2756

132. Roussel A, Yang Y, Ferrato F et al (1998) Structure and activity of rat pancreatic lipase-related protein 2. J Biol Chem 273:32121-32128

133. Giller T, Buchwald P, Blum-Kaelin D et al (1992) Two novel human pancreatic lipase related proteins, hPLRP1 and hPLRP2. J Biol Chem 267:16509-16516 
134. Rogalska E, Ransac S, Verger R (1993) Controlling lipase stereoselectivity via the surface pressure. J Biol Chem 268:792-794

135. Rogalska E, Cudrey C, Ferrato F, Verger R (1993) Stereoselective hydrolysis of triglycerides by animal and microbial lipases. Chirality 5:24-30

136. Paltauf F, Esfandi F, Holasek A (1974) Stereospecificity of lipases. Enzymic hydrolysis of enantiomeric alkyl diacylglycerols by lipoprotein lipase, lingual lipase and pancreatic lipase. FEBS Lett 40:119-123

137. Jensen RG, DeJong FA, Clark RM et al (1982) Stereospecificity of premature human infant lingual lipase. Lipids 17:570-572

138. Wang CS, Kuksis A, Manganaro F et al (1983) Studies on the substrate specificity of purified human milk bile salt-activated lipase. J Biol Chem 258:9197-9202

139. Morley N, Kuksis A (1972) Positional specificity of lipoprotein lipase. J Biol Chem 247:6389-6393

140. Akesson B, Gronowitz S, Herslof B (1976) Stereospecificity of hepatic lipases. FEBS Lett 71:241-244

141. Mechoulam R, Ben-Shabat S, Hanus L et al (1995) Identification of an endogenous 2-monoglyceride, present in canine gut, that binds to cannabinoid receptors. Biochem Pharmacol 50:83-90

142. Sugiura T, Kondo S, Sukagawa A et al (1995) 2-Arachidonoylglycerol: a possible endogenous cannabinoid receptor ligand in brain. Biochem Biophys Res Commun 215:89-97

143. Schicho R, Storr M (2014) Cannabis finds its way into treatment of Crohn's disease. Pharmacology 93:1-3

144. Bashashati M, Nasser Y, Keenan C et al (2015) Inhibiting endocannabinoid biosynthesis: a novel approach to the treatment of constipation. Br J Pharmacol 172(12):3099-3111

145. Taschler U, Eichmann TO, Radner FPW et al (2015) Monoglyceride lipase-deficiency causes desensitization of intestinal cannabinoid receptor type 1 and increased colonic $\mu$-opioid receptor sensitivity. Br J Pharmacol [Epub ahead of print]

146. Cases S, Smith SJ, Zheng YW et al (1998) Identification of a gene encoding an acyl CoA:diacylglycerol acyltransferase, a key enzyme in triacylglycerol synthesis. Proc Natl Acad Sci USA 95:13018-13023

147. Hofmann K (2000) A superfamily of membrane-bound $O$ acyltransferases with implications for wnt signaling. Trends Biochem Sci 25:111-112

148. Yen CL, Stone SJ, Koliwad S et al (2008) Thematic review series: glycerolipids. DGAT enzymes and triacylglycerol biosynthesis. J Lipid Res 49:2283-2301

149. Stone SJ, Levin MC, Zhou P et al (2009) The endoplasmic reticulum enzyme DGAT2 is found in mitochondria-associated membranes and has a mitochondrial targeting signal that promotes its association with mitochondria. J Biol Chem 284:5352-5361

150. McFie PJ, Stone SL, Banman SL, Stone SJ (2010) Topological orientation of acyl-CoA:diacylglycerol acyltransferase-1 (DGAT1) and identification of a putative active site histidine and the role of the $\mathrm{n}$ terminus in dimer/tetramer formation. J Biol Chem 285:37377-37387

151. Siloto RMP, Madhavji M, Wiehler WB et al (2008) An N-terminal fragment of mouse DGAT1 binds different acyl-CoAs with varying affinity. Biochem Biophys Res Commun 373:350-354

152. Cheng D, Meegalla RL, He B et al (2001) Human acyl-CoA:diacylglycerol acyltransferase is a tetrameric protein. Biochem $\mathrm{J}$ 359:707-714

153. Owen MR, Corstorphine CC, Zammit VA (1997) Overt and latent activities of diacylglycerol acyltransferase in rat liver microsomes: possible roles in very-low-density lipoprotein triacylglycerol secretion. Biochem J 323(1):17-21
154. Wurie HR, Bucketts L, Zammit VA (2011) Evidence that diacylglycerol acyltransferase 1 (DGAT1) has dual membrane topology in the endoplasmic reticulum of HepG2 cells. J Biol Chem 286:36238-36247

155. Yen CL, Monetti M, Burri BJ Jr, Farese RV (2005) The triacylglycerol synthesis enzyme DGAT1 also catalyzes the synthesis of diacylglycerols, waxes, and retinyl esters. J Lipid Res 46:1502-1511

156. Lardizabal KD, Mai JT, Wagner NW et al (2001) DGAT2 is a new diacylglycerol acyltransferase gene family: purification, cloning, and expression in insect cells of two polypeptides from Mortierella ramanniana with diacylglycerol acyltransferase activity. J Biol Chem 276:38862-38869

157. Stone SJ, Levin MC Jr, Farese RV (2006) Membrane topology and identification of key functional amino acid residues of murine acyl-CoA:diacylglycerol acyltransferase-2. J Biol Chem 281:40273-40282

158. Alam M, Gilham D, Vance DE, Lehner R (2006) Mutation of F417 but not of L418 or L420 in the lipid binding domain decreases the activity of triacylglycerol hydrolase. J Lipid Res 47:375-383

159. Kuerschner L, Moessinger C, Thiele C (2008) Imaging of lipid biosynthesis: how a neutral lipid enters lipid droplets. Traffic 9:338-352

160. McFie PJ, Banman SL, Kary S, Stone SJ (2011) Murine diacylglycerol acyltransferase-2 (DGAT2) can catalyze triacylglycerol synthesis and promote lipid droplet formation independent of its localization to the endoplasmic reticulum. J Biol Chem 286:28235-28246

161. Stone SJ, Myers HM, Watkins SM et al (2004) Lipopenia and skin barrier abnormalities in DGAT2-deficient mice. J Biol Chem 279:11767-11776

162. Hiramine Y, Tanabe T (2011) Characterization of acyl-coenzyme A: diacylglycerol acyltransferase (DGAT) enzyme of human small intestine. J Physiol Biochem 67:259-264

163. Smith SJ, Cases S, Jensen DR et al (2000) Obesity resistance and multiple mechanisms of triglyceride synthesis in mice lacking Dgat. Nat Genet 25:87-90

164. Wurie HR, Buckett L, Zammit VA (2012) Diacylglycerol acyltransferase 2 (DGAT2) acts upstream of DGAT1, and utilises nascent diglycerides and de novo synthesised fatty acids in HepG2 cells. FEBS J 279(17):3033-3047

165. Qi J, Lang W, Geisler JG et al (2012) The use of stable isotopelabeled glycerol and oleic acid to differentiate the hepatic functions of DGAT1 and -2. J Lipid Res 53:1106-1116

166. Bisogno T, Howell F, Williams $G$ et al (2003) Cloning of the first sn1-DAG lipases points to the spatial and temporal regulation of endocannabinoid signaling in the brain. J Cell Biol 163:463-468

167. Gao Y, Vasilyev DV, Goncalves MB et al (2010) Loss of retrograde endocannabinoid signaling and reduced adult neurogenesis in diacylglycerol lipase knock-out mice. J Neurosci 30:2017-2024

168. Jung K, Astarita G, Thongkham D, Piomelli D (2011) Diacylglycerol lipase-alpha and -beta control neurite outgrowth in neuro-2a cells through distinct molecular mechanisms. Mol Pharmacol 80:60-67

169. Wood R, Harlow RD (1969) Structural analyses of rat liver phosphoglycerides. Arch Biochem Biophys 135:272-281

170. Marai L, Kuksis A (1969) Molecular species of lecithins from erythrocytes and plasma of man. J Lipid Res 10:141-152

171. Ligresti A, Petrosino S, Di Marzo V (2009) From endocannabinoid profiling to "endocannabinoid therapeutics". Curr Opin Chem Biol 13:321-331

172. Merida I, Avila-Flores A, Merino E (2008) Diacylglycerol kinases: at the hub of cell signalling. Biochem J 409:1-18 
173. Sakane F, Imai S, Kai M et al (2007) Diacylglycerol kinases: why so many of them? Biochim Biophys Acta 1771:793-806

174. Topham MK, Epand RM (2009) Mammalian diacylglycerol kinases: molecular interactions and biological functions of selected isoforms. Biochim Biophys Acta 1790:416-424

175. Topham MK, Prescott SM (1999) Mammalian diacylglycerol kinases, a family of lipid kinases with signaling functions. J Biol Chem 274:11447-11450

176. Goto K, Hozumi Y, Nakano T et al (2008) Lipid messenger, diacylglycerol, and its regulator, diacylglycerol kinase, in cells, organs, and animals: history and perspective. Tohoku J Exp Med 214:199-212

177. Shulga YV, Topham MK, Epand RM (2011) Regulation and functions of diacylglycerol kinases. Chem Rev 111:6186-6208

178. Boni LT, Rando RR (1985) The nature of protein kinase C activation by physically defined phospholipid vesicles and diacylglycerols. J Biol Chem 260:10819-10825

179. Rando RR, Young N (1984) The stereospecific activation of protein kinase C. Biochem Biophys Res 122:818-823

180. Nomura H, Ase K, Sekiguchi K et al (1986) Stereospecificity of diacylglycerol for stimulus-response coupling in platelets. Biochem Biophys Res Commun 140:1143-1151

181. Epand RM, Shulga YV, Timmons HC et al (2007) Substrate chirality and specificity of diacylglycerol kinases and the multisubstrate lipid kinase. Biochemistry 46:14225-14231

182. Tang W, Bunting M, Zimmerman GA et al (1996) Molecular cloning of a novel human diacylglycerol kinase highly selective for arachidonate-containing substrates. J Biol Chem 271:10237-10241

183. Lung M, Shulga YV, Ivanova PT et al (2009) Diacylglycerol kinase $\varepsilon$ is selective for both acyl chains of phosphatidic acid or diacylglycerol. J Biol Chem 284:31062-31073

184. De Turco EBR, Tang W, Topham MK et al (2001) Diacylglycerol kinase epsilon regulates seizure susceptibility and longterm potentiation through arachidonoyl- inositol lipid signaling. Proc Natl Acad Sci USA 98:4740-4745

185. Henneberry AL, McMaster CR (1999) Cloning and expression of a human choline/ethanolaminephosphotransferase: synthesis of phosphatidylcholine and phosphatidylethanolamine. Biochem J 339(Pt 2):291-298

186. Henneberry AL, Wistow G, McMaster CR (2000) Cloning, genomic organization, and characterization of a human cholinephosphotransferase. J Biol Chem 275:29808-29815

187. Henneberry AL, Wright MM, McMaster CR (2002) The major sites of cellular phospholipid synthesis and molecular determinants of Fatty Acid and lipid head group specificity. Mol Biol Cell 13:3148-3161

188. McMaster CR, Bell RM (1997) CDP-choline:1,2-diacylglycerol cholinephosphotransferase. Biochim Biophys Acta 1348: $100-110$

189. Hjelmstad RH, Morash SC, McMaster CR, Bell RM (1994) Chimeric enzymes. Structure-function analysis of segments of sn-1,2-diacylglycerol choline- and ethanolaminephosphotransferases. J Biol Chem 269:20995-21002

190. McMaster CR, Bell RM (1997) CDP-ethanolamine:1,2-diacylglycerol ethanolaminephosphotransferase. Biochim Biophys Acta 1348:117-123

191. McMaster CR, Bell RM (1994) Phosphatidylcholine biosynthesis in Saccharomyces cerevisiae. Regulatory insights from studies employing null and chimeric sn-1,2-diacylglycerol choline- and ethanolaminephosphotransferases. J Biol Chem 269:28010-28016

192. McGee TP, Skinner HB, Bankaitis VA (1994) Functional redundancy of CDP-ethanolamine and CDP-choline pathway enzymes in phospholipid biosynthesis: ethanolamine-dependent effects on steady-state membrane phospholipid composition in Saccharomyces cerevisiae. J Bacteriol 176:6861-6868

193. Samborski RW, Ridgway ND, Vance DE (1990) Evidence that only newly made phosphatidylethanolamine is methylated to phosphatidylcholine and that phosphatidylethanolamine is not significantly deacylated-reacylated in rat hepatocytes. J Biol Chem 265:18322-18329

194. Dietrich A, Kalwa H, Rost BR, Gudermann T (2005) The diacylglycerol-sensitive TRPC3/6/7 subfamily of cation channels: functional characterization and physiological relevance. Pflugers Arch Eur J Physiol 451:72-80

195. Vazquez G, Tano JY, Smedlund K (2010) On the potential role of source and species of diacylglycerol in phospholipase-dependent regulation of TRPC3 channels. Channels (Austin) $4: 232-240$

196. Steinberg SF (2008) Structural basis of protein kinase C isoform function. Physiol Rev 88:1341-1378

197. Turban S, Hajduch E (2011) Protein kinase C isoforms: mediators of reactive lipid metabolites in the development of insulin resistance. FEBS Lett 585:269-274

198. Newton AC (2001) Protein kinase C: structural and spatial regulation by phosphorylation, cofactors, and macromolecular interactions. Chem Rev 101:2353-2364

199. Silinsky EM, Searl TJ (2003) Phorbol esters and neurotransmitter release: more than just protein kinase $\mathrm{C}$ ? Br J Pharmacol 138:1191-1201

200. Brose N, Rosenmund C (2002) Move over protein kinase C, you've got company: alternative cellular effectors of diacylglycerol and phorbol esters. J Cell Sci 115:4399-4411

201. Kazanietz MG (2002) Novel "nonkinase" phorbol ester receptors: the $\mathrm{C} 1$ domain connection. Mol Pharmacol 61:759-767

202. Kazanietz MG (2000) Eyes, wide shut: protein kinase C isozymes are not the only receptors for the phorbol ester tumor promoters. Mol Carcinog 28:5-11

203. Ron D, Kazanietz MG (1999) New insights into the regulation of protein kinase $\mathrm{C}$ and novel phorbol ester receptors. FASEB J 13:1658-1676

204. Colón-González F, Kazanietz MG (2006) C1 domains exposed: from diacylglycerol binding to protein-protein interactions. Biochim Biophys Acta Mol Cell Biol Lipids 1761:827-837

205. Yang C, Kazanietz MG (2003) Divergence and complexities in DAG signaling: looking beyond PKC. Trends Pharmacol Sci 24:602-608

206. Herrera R, Shivers BD (1994) Expression of alpha 1-chimaerin (rac-1 GAP) alters the cytoskeletal and adhesive properties of fibroblasts. J Cell Biochem 56:582-591

207. Clyde-Smith J, Silins G, Gartside M et al (2000) Characterization of RasGRP2, a plasma membrane-targeted, dual specificity Ras/Rap exchange factor. J Biol Chem 275:32260-32267

208. Dupuy AJ, Morgan K, Von Lintig FC et al (2001) Activation of the Rap1 guanine nucleotide exchange gene, CalDAG-GEF I, in BXH-2 murine myeloid leukemia. J Biol Chem 276:11804-11811

209. Augustin I, Betz A, Herrmann C et al (1999) Differential expression of two novel Munc13 proteins in rat brain. Biochem $\mathrm{J}$ 337(Pt 3):363-371

210. Augustin I, Rosenmund C, Südhof TC, Brose N (1999) Munc131 is essential for fusion competence of glutamatergic synaptic vesicles. Nature 400:457-461

211. Aravamudan B, Fergestad T, Davis WS et al (1999) Drosophila UNC-13 is essential for synaptic transmission. Nat Neurosci 2:965-971

212. Ashery U, Varoqueaux F, Voets T et al (2000) Munc13-1 acts as a priming factor for large dense-core vesicles in bovine chromaffin cells. EMBO J 19:3586-3596 
213. Jamora C, Yamanouye N, Van Lint J et al (1999) Gbetagammamediated regulation of Golgi organization is through the direct activation of protein kinase D. Cell 98:59-68

214. Liljedahl M, Maeda Y, Colanzi A et al (2001) Protein kinase D regulates the fission of cell surface destined transport carriers from the trans-Golgi network. Cell 104:409-420

215. Litherland GJ, Hajduch E, Hundal HS (2001) Intracellular signalling mechanisms regulating glucose transport in insulinsensitive tissues (review). Mol Membr Biol 18:195-204

216. Pearce LR, Komander D, Alessi DR (2010) The nuts and bolts of AGC protein kinases. Nat Rev Mol Cell Biol 11:9-22

217. Sano H, Kane S, Sano E et al (2003) Insulin-stimulated phosphorylation of a Rab GTPase-activating protein regulates GLUT4 translocation. J Biol Chem 278:14599-14602

218. Samuel VT, Petersen KF, Shulman GI (2010) Lipid-induced insulin resistance: unravelling the mechanism. Lancet 375:2267-2277

219. Samuel VT, Liu ZX, Wang A et al (2007) Inhibition of protein kinase Cepsilon prevents hepatic insulin resistance in nonalcoholic fatty liver disease. J Clin Invest 117:739-745

220. Li Y, Soos TJ, Li X et al (2004) Protein kinase C Theta inhibits insulin signaling by phosphorylating IRS1 at Ser(1101). J Biol Chem 279:45304-45307

221. Nagle CA, An J, Shiota M et al (2007) Hepatic overexpression of glycerol-sn-3-phosphate acyltransferase 1 in rats causes insulin resistance. J Biol Chem 282:14807-14815

222. Turinsky J, O'Sullivan DM, Bayly BP (1990) 1,2-Diacylglycerol and ceramide levels in insulin-resistant tissues of the rat in vivo. J Biol Chem 265:16880-16885

223. Jornayvaz FR, Jurczak MJ, Lee HY et al (2010) A high-fat, ketogenic diet causes hepatic insulin resistance in mice, despite increasing energy expenditure and preventing weight gain. Am J Physiol Metab 299:E808-E815

224. Monetti M, Levin MC, Watt MJ et al (2007) Dissociation of hepatic steatosis and insulin resistance in mice overexpressing DGAT in the liver. Cell Metab 6:69-78

225. Jornayvaz FR, Birkenfeld AL, Jurczak MJ et al (2011) Hepatic insulin resistance in mice with hepatic overexpression of diacylglycerol acyltransferase 2. Proc Natl Acad Sci USA 108:5748-5752

226. Jornayvaza F, Shulman GI, Jornayvaz FR, Shulman GI (2012) Diacylglycerol activation of protein kinase Cepsilon and hepatic insulin resistance. Cell Metab 15:574-584

227. Kumashiro N, Erion DM, Zhang D et al (2011) Cellular mechanism of insulin resistance in nonalcoholic fatty liver disease. Proc Natl Acad Sci USA 108:16381-16385

228. Mulder H, Sorhede-Winzell M, Contreras JA et al (2003) Hormone-sensitive lipase null mice exhibit signs of impaired insulin sensitivity whereas insulin secretion is intact. J Biol Chem 278:36380-36388

229. Roduit R, Masiello P, Wang SP et al (2001) A role for hormonesensitive lipase in glucose-stimulated insulin secretion: a study in hormone-sensitive lipase-deficient mice. Diabetes 50:1970-1975

230. Voshol PJ, Haemmerle G, Ouwens DM et al (2003) Increased hepatic insulin sensitivity together with decreased hepatic triglyceride stores in hormone-sensitive lipase-deficient mice. Endocrinology 144:3456-3462

231. Park SY, Kim HJ, Wang S et al (2005) Hormone-sensitive lipase knockout mice have increased hepatic insulin sensitivity and are protected from short-term diet-induced insulin resistance in skeletal muscle and heart. Am J Physiol Metab 289:E30-E39

232. Albert JS, Yerges-Armstrong LM, Horenstein RB et al (2014) Null mutation in hormone-sensitive lipase gene and risk of type 2 diabetes. N Engl J Med 370:2307-2315

233. Brown JM, Betters JL, Lord C et al (2010) CGI-58 knockdown in mice causes hepatic steatosis, but prevents diet-induced obesity and glucose intolerance. J Lipid Res 51:3306-3315

234. Cantley JL, Yoshimura T, Camporez JPG et al (2013) CGI-58 knockdown sequesters diacylglycerols in lipid droplets/ERpreventing diacylglycerol-mediated hepatic insulin resistance. Proc Natl Acad Sci USA 110:1869-1874

235. Badin PM, Louche K, Mairal A et al (2011) Altered skeletal muscle lipase expression and activity contribute to insulin resistance in humans. Diabetes 60:1734-1742

236. Ahmadian M, Duncan RE, Varady KA et al (2009) Adipose overexpression of desnutrin promotes fatty acid use and attenuates diet-induced obesity. Diabetes 58:855-866

237. Sato M, Ueda Y, Umezawa Y (2006) Imaging diacylglycerol dynamics at organelle membranes. Nat Methods 3:797-799

238. Kunkel MT, Newton AC (2010) Calcium transduces plasma membrane receptor signals to produce diacylglycerol at golgi membranes. J Biol Chem 285:22748-22752

239. Ueda Y, Makino A, Murase-Tamada K et al (2013) Sphingomyelin regulates the transbilayer movement of diacylglycerol in the plasma membrane of Madin-Darby canine kidney cells. FASEB J 27:3284-3297

240. Wakelam MJO (1998) Diacylglycerol: when is it an intracellular messenger? Biochim Biophys Acta Mol Cell Biol Lipids 1436:117-126

241. Becker KB, Hannun YA (2012) Bioactive Lipids. In: Nicolaou A, Kokotos G (eds) Bioact Lipids. p 37-61

242. Carrasco S, Mérida I (2007) Diacylglycerol, when simplicity becomes complex. Trends Biochem Sci 32:27-36 